NUREG-1607

\title{
Safety Evaluation Report related to the Department of Energy's proposal for the irradiation of lead test assemblies containing tritium-producing burnable absorber rods in commercial light-water reactors
}

Project No. 697

Manuscript Completed: May 1997

Date Published: May 1997

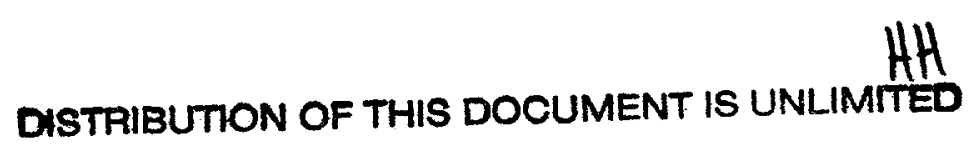

Division of Reactor Program Management

Office of Nuclear Reactor Regulation

U.S. Nuclear Regulatory Commission

Washington, DC 20555-0001

\section{DISCLAIMER}

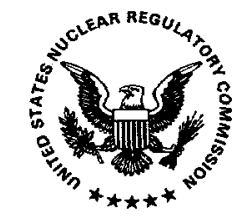

This report was prepared as an account of work sponsored by an agency of the United States Government. Neither the United States Government nor any agency thereof, nor any of their employees, makes any warranty, express or implied, or assumes any legal liability or responsibility for the accuracy, completeness, or usefulness of any information, apparatus, product, or process disclosed, or represents that its use would not infringe privately owned rights. Reference herein to any specific commercial product, process, or service by trade name, trademark, manufacturer, or otherwise does not necessarily constitute or imply its endorsement, recommendation, or favoring by the United States Government or any agency thereof. The views and opinions of authors expressed herein do not necessarily state or reflect those of the United States Government or any agency thereof. 



\section{DISCLATMER}

Portions of this document may be illegible in electronic image products. Images are produced from the best available original document. 


\begin{abstract}
The Department of Energy (DOE) is responsible for establishing the capability to produce tritium, an essential material used in U.S. nuclear weapons, by the end of 2005 , in accordance with a Presidential decision directive.

Under the terms of the Joint DOE/NRC Memorandum of Understanding of May 22, 1996, NRC is providing review and consultation services to assist DOE in assessing and resolving technical and licensing issues associated with DOE's proposal for the production of tritium in a commercial light-water reactor (CLWR).

DOE has submitted a report, as revised, containing sufficient information for the staff to determine whether the use of a CLWR to irradiate a limited number of tritium-producing burnable absorber rods (TPBARs) in lead test assemblies (LTAs) raises generic issues involving an unreviewed safety question, as defined in 10 CFR 50.59. The NRC staff has reviewed the DOE report and has prepared this safety evaluation to address the acceptability of the proposed irradiation and whether a licensee can undertake the irradiation of these LTAs in accordance with the provisions of 10 CFR 50.59 without NRC licensing action.
\end{abstract}

This safety evaluation is being transmitted to the Commission before issuance.

As summarized in Section 10 of this safety evaluation, the staff has identified issues that require further NRC review. The staff has also identified a number of areas in which an individual licensee undertaking irradiation of TPBAR LTAs will have to supplement the information in the DOE report before the staff can determine whether the proposed irradiation is acceptable at a particular facility.

Therefore, the staff concludes that a licensee undertaking irradiation of TPBAR LTAs in a CLWR will have to submit an application for amendment to its facility operating license before inserting the LTAs into the reactor. 



\section{TABLE OF CONTENTS}

Section $\quad \underline{\text { Page }}$

ABSTRACT $\ldots \ldots \ldots \ldots \ldots \ldots \ldots \ldots \ldots \ldots \ldots \ldots \ldots \ldots \ldots \ldots \ldots \ldots \ldots \ldots \ldots \ldots \ldots$

ABBREVIATIONS $\ldots \ldots \ldots \ldots \ldots \ldots \ldots \ldots \ldots \ldots \ldots \ldots \ldots \ldots \ldots \ldots \ldots \ldots \ldots$

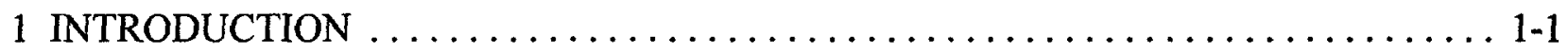

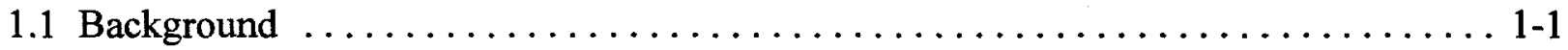

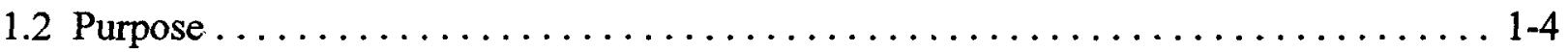

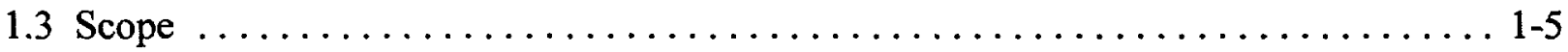

1.4 Organization of This Safety Evaluation $\ldots \ldots \ldots \ldots \ldots \ldots \ldots \ldots \ldots \ldots \ldots \ldots \ldots$

2 TRITIUM-PRODUCING BURNABLE ABSORBER ROD LEAD TEST ASSEMBLY

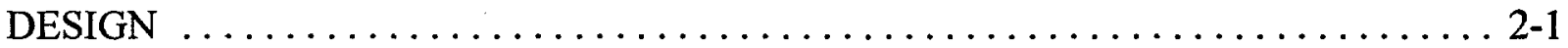

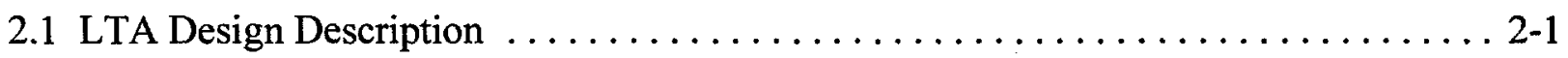

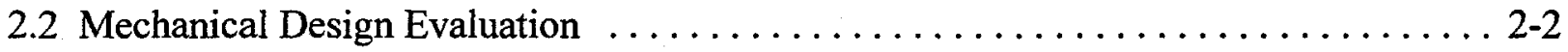

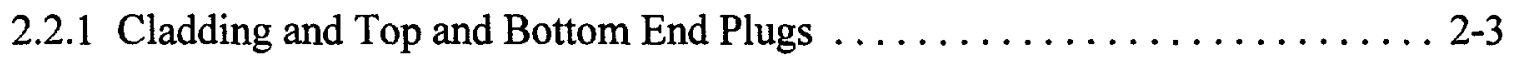

2.2 .2 Absorber Pellets . . . . . . . . . . . . . . . . . . . . . 2-7

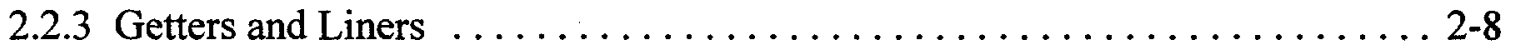

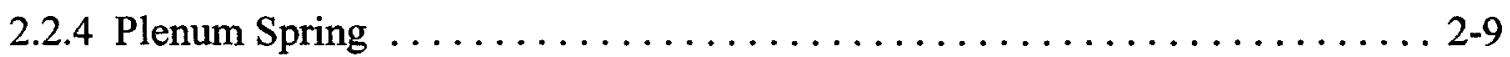

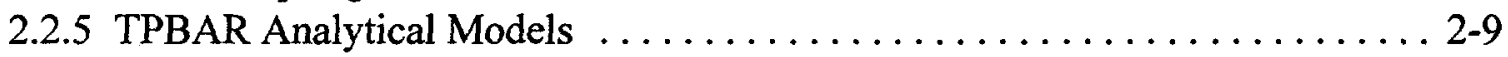

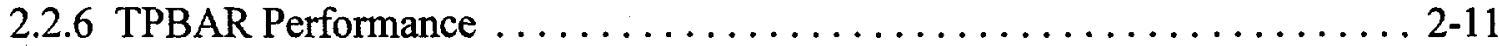

2.3 Surveillance Program . . . . . . . . . . . . . . . . . . . . . . . 2-14

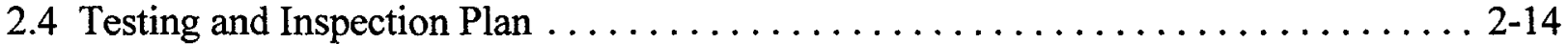

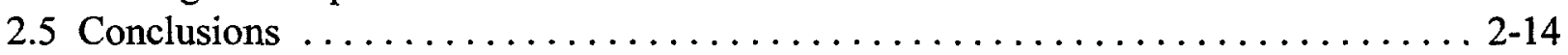

3 NUCLEAR DESIGN DESCRIPTION $\ldots \ldots \ldots \ldots \ldots \ldots \ldots \ldots \ldots \ldots \ldots \ldots \ldots$

3.1 Effects on Reactor Nuclear Design $\ldots \ldots \ldots \ldots \ldots \ldots \ldots \ldots \ldots \ldots \ldots \ldots \ldots$

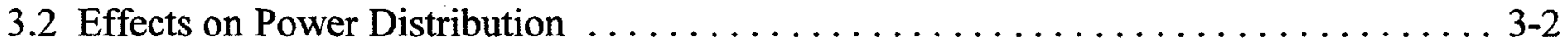


Section

Page

3.3 Effects on Control Requirements $\ldots \ldots \ldots \ldots \ldots \ldots \ldots \ldots \ldots \ldots \ldots \ldots \ldots \ldots$

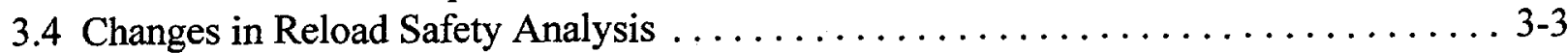

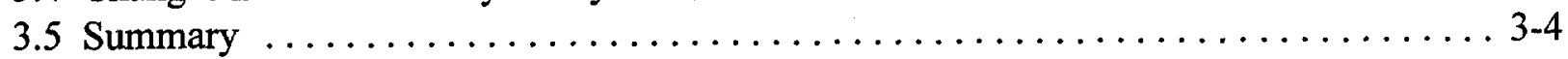

4 THERMAL AND HYDRAULIC DESIGN $\ldots \ldots \ldots \ldots \ldots \ldots \ldots \ldots \ldots \ldots \ldots$

4.1 TPBAR Thermal-Hydraulic Design $\ldots \ldots \ldots \ldots \ldots \ldots \ldots \ldots \ldots \ldots \ldots \ldots .1$

4.2 Impact on Reactor Core Thermal-Hydraulic Design . . . . . . . . . . . . . . 4-2

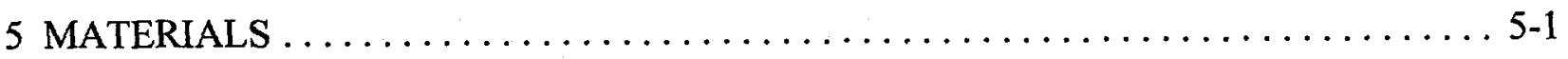

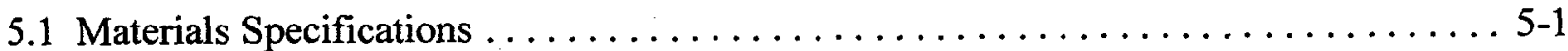

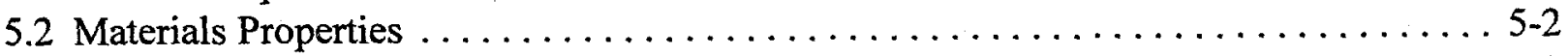

5.3 Materials Performance . . . . . . . . . . . . . . . . . . . .

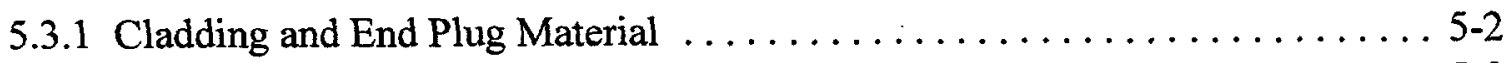

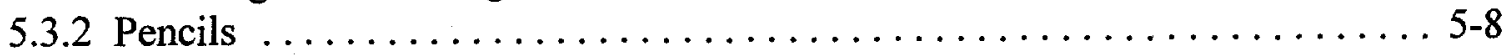

5.3 .3 Absorber Pellets . . . . . . . . . . . . . . . . . . . . . . 5-8

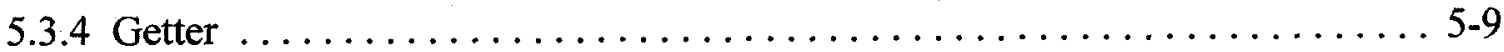

5.3 .5 Liner . . . . . . . . . . . . . . . . . . . . . . . . . . . . . . . . . .

5.3 .6 Plenum Subassembly and Getter Disk . . . . . . . . . . . . . . 5-9

5.3 .7 LTA Hold-Down Assembly . . . . . . . . . . . . . . . . . 5-10

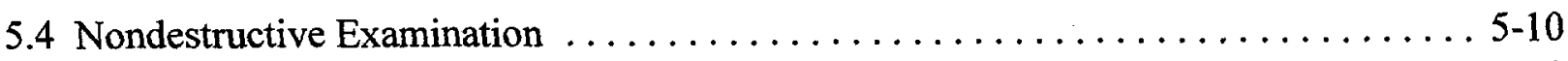

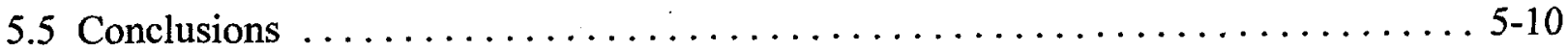

6 OPERATIONAL IMPACTS OF LTAs $\ldots \ldots \ldots \ldots \ldots \ldots \ldots \ldots \ldots \ldots \ldots \ldots \ldots \ldots$

6.1 Normal Operations . . . . . . . . . . . . . . . . . . . . . . . . . 6-1

6.2 Refueling Operations $\ldots \ldots \ldots \ldots \ldots \ldots \ldots \ldots \ldots \ldots \ldots \ldots \ldots \ldots \ldots \ldots$

6.2.1 TPBAR Assembly Storage in Fuel Pool or New Fuel Storage . . . . . . . . 6-1

6.2 .2 Onsite TPBAR Assembly Movement and Handling . . . . . . . . . . . 6-2

6.2 .3 Occupational Exposure During Refueling $\ldots \ldots \ldots \ldots \ldots \ldots \ldots \ldots .6 \ldots \ldots$

6.3 Offnormal Events $\ldots \ldots \ldots \ldots \ldots \ldots \ldots \ldots \ldots \ldots \ldots \ldots \ldots \ldots \ldots . \ldots \ldots$ 
$\underline{\text { Section }}$

Page

6.3.1 Impacts of TPBAR Absorber Relocation $\ldots \ldots \ldots \ldots \ldots \ldots \ldots \ldots .6 \ldots \ldots$

6.3.2 TPBAR Cladding Defects $\ldots \ldots \ldots \ldots \ldots \ldots \ldots \ldots \ldots \ldots \ldots .6 \ldots \ldots$

6.3.3 Radiological Consequences of a TPBAR Cladding Breach $\ldots \ldots \ldots \ldots .6-4$

6.3.4 Inadvertent Loading and Operation of an LTA in an Improper Position .......................... 6-5

6.3.5 Anticipated Transient Without Scram (ATWS) ............... 6-6

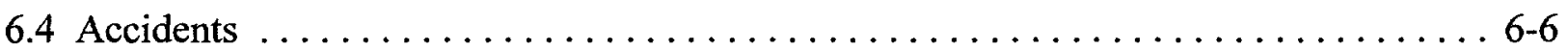

6.4.1 Impacts of a Dropped LTA $\ldots \ldots \ldots \ldots \ldots \ldots \ldots \ldots \ldots \ldots .6 .6$

6.4.2 Impacts of Design Tritium Leakage on Radiological

Consequences of a Steam Generator Tube Rupture or

Steamline Break .............................. 6-7

6.4 .3 Impacts of LTAs in the Event of a LOCA .................. 6-7

6.5 Summary $\ldots \ldots \ldots \ldots \ldots \ldots \ldots \ldots \ldots \ldots \ldots \ldots \ldots \ldots \ldots, 6,8$

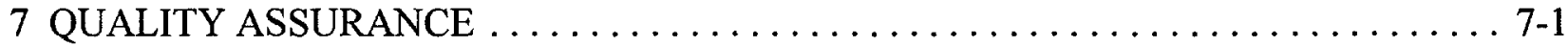

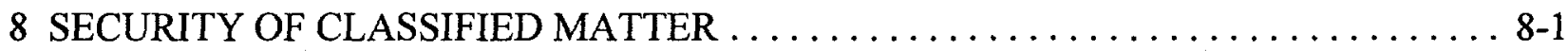

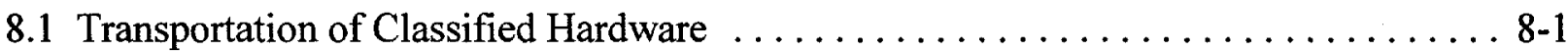

8.2 Control of Classified Documents and Hardware $\ldots \ldots \ldots \ldots \ldots \ldots \ldots \ldots . .6$. 1

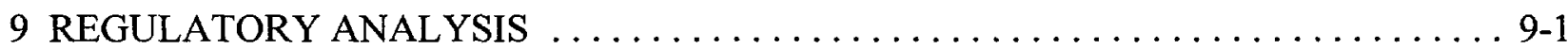

9.1 Effect on Plant Technical Specifications ........................ 9-1

9.2 Effect on Plant Final Safety Analysis Report $\ldots \ldots \ldots \ldots \ldots \ldots \ldots \ldots \ldots . . \ldots .1$

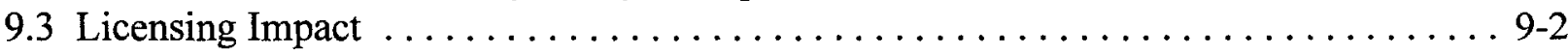

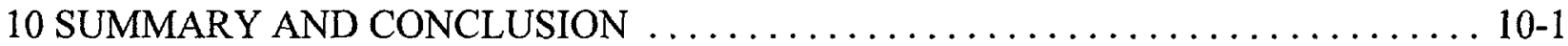

10.1 Issues Requiring Further NRC Review . . . . . . . . . . . . . . . . . . 10-1

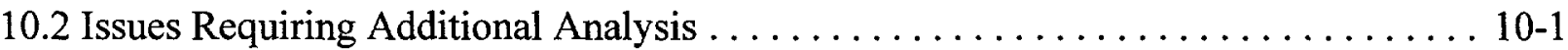

APPENDIX A-CHRONOLOGY OF CORRESPONDENCE $\ldots \ldots \ldots \ldots \ldots \ldots \ldots$ A-1 



\section{ABBREVIATIONS}

ACRS

AISI

ALARA

ASME

ASTM

ATR

ATWS

BOL

BPRA

BWR

CLWR

CMTR

$\mathrm{CW}$

DBA

DBLOCA

DOE

DORT

EFPD

EOL

ETR

FCL

FSAR

GVR

HFIR

IGSCC intergranular stress corrosion cracking

LBLOCA large-break loss-of-coolant accident

LTA

Advisory Committee on Reactor Safeguards

American Iron and Steel Institute

as low as reasonably achievable

American Society of Mechanical Engineers

American Society for Testing and Materials

Advanced Test Reactor

anticipated transient without scram

beginning of life

burnable poison rod assembly

boiling-water reactor

commercial light-water reactor

certified material test report

cold-worked

design-basis accident

design-basis loss-of-coolant accident

Department of Energy

discrete ordinate transport (code)

effective full-power day

end of life

Engineering Test Reactor

facilities (security) clearance

final safety analysis report

gas volume ratio

High Flux Isotope Reactor

lead test assembly 


\begin{tabular}{|c|c|}
\hline MCNP & Monte Carlo N-Particle (Transport Code Version 4A) \\
\hline MPH & Materials Property Handbook \\
\hline MOU & memorandum of understanding \\
\hline NDE & nondestructive examination \\
\hline NPZ & nickel-plated Zircaloy-4 \\
\hline NRC & Nuclear Regulatory Commission \\
\hline OBE & operating-basis earthquake \\
\hline ODCM & offsite dose calculation manual \\
\hline PIE & post-irradiation examination \\
\hline PNNL & Pacific Northwest National Laboratory \\
\hline PRF & permeation reduction factor \\
\hline PWR & pressurized-water reactor \\
\hline QA & quality assurance \\
\hline RCS & reactor coolant system \\
\hline SAR & safety analysis report \\
\hline SBLOCA & small-break loss-of-coolant accident \\
\hline $\mathrm{SCC}$ & stress corrosion cracking \\
\hline SRM & staff requirements memorandum \\
\hline SS & stainless steel \\
\hline SSE & safe-shutdown earthquake \\
\hline TGSCC & transgranular stress corrosion cracking \\
\hline TPBAR & tritium-producing burnable absorber rod \\
\hline TS & Technical Specifications \\
\hline TVA & Tennessee Valley Authority \\
\hline WABA & wet annular burnable assembly \\
\hline
\end{tabular}




\section{INTRODUCTION}

On December 4, 1996, the Department of Energy (DOE) submitted a report prepared by Pacific Northwest National Laboratory (PNNL), PNNL-11419, "Report on the Evaluation of the Tritium Producing Burnable Absorber Rod Lead Test Assembly" (the DOE report), to present technical information related to irradiation of tritium-producing burnable absorber rods (TPBARs) in a commercial light-water reactor (CLWR). DOE submitted Revision 1 to this report on March 3, 1997 , in order to respond to the staff's requests for additional information of January 3 and 13, 1997.

\subsection{Background}

Tritium, an essential material in U.S. nuclear weapons, is an isotope of hydrogen that decays at a rate of approximately 5 percent per year (a 12.3-year half-life). The United States has not produced tritium since 1988, when DOE closed its production facility at Savannah River. Current, short-term tritium needs are being met by recycling tritium from dismantled U.S. nuclear weapons. Resumption of tritium production will be essential for maintaining the U.S. nuclear weapons stockpile and the U.S. nuclear deterrent.

\section{DOE's Dual-Path Strategy for the Production of Tritium}

DOE is responsible for establishing the capability to produce tritium by the end of 2005 , in accordance with a Presidential decision directive. DOE has selected a dual-path strategy to meet the schedule. One path is the accelerator production of tritium. If DOE adopts an accelerator design utilizing a tungsten target (as is currently contemplated), it may pursue that option without Commission approval because the NRC does not have statutory authority to regulate accelerators or DOE production facilities.

The other path is one that could require NRC oversight. DOE proposes to produce tritium in CLWRs, either through acquisition of reactor(s) under Government ownership or by contracting for target irradiation services at a plant under private ownership. Production of tritium in an NRC-regulated CLWR would involve NRC oversight.

Regardless of which option is selected as the primary approach for tritium production, DOE intends to complete confirmatory testing, fabricate the first core load of targets, and develop a new extraction capability as a contingency to meet national defense requirements. Tritium extraction would take place at DOE's Savannah River Plant and would not involve oversight by NRC. 


\section{Joint DOE/NRC Memorandum of Understanding}

On May 22, 1996, the Secretary of Energy and the Chairman of the Nuclear Regulatory Commission signed a Joint DOE/NRC Memorandum of Understanding (MOU). This MOU establishes the basis for NRC review and consultation concerning DOE's possible use of CLWRs for producing tritium. It supplements an earlier MOU between DOE and NRC (dated February 24,1978 ) and relates solely to NRC's review of and consultation on DOE's proposal for tritium production in CLWRs. The MOU acknowledges that an issue exists involving the use of civilian commercial reactors to support military requirements but stipulates that NRC will not be involved, either in a policy or a technical role, in resolution of that issue. The MOU also stipulates that NRC will not be involved in the decision on whether to use an accelerator or a CLWR to produce tritium.

Under the terms of the MOU, NRC is providing review and consultation services to assist DOE in assessing and resolving technical and licensing issues associated with CLWR production of tritium (including physical security, security clearance, and environmental issues) in order to support a Secretarial decision on the primary and backup tritium production approaches in late 1998.

Finally, the MOU contemplates that the NRC will recover costs associated with this program through a reimbursable agreement between the two agencies. Therefore, the cost of this review will not be split among NRC licensees to be paid as part of the annual fee under 10 CFR Part 171 to cover NRC overhead, general, and administrative costs.

\section{CLWR Production of Tritium}

DOE has developed a design for burnable poison rods using lithium, rather than boron, in pressurized-water reactor (PWR) fuel assemblies. As a result of irradiation by neutrons in the reactor core, some of the lithium in the target rods is converted to tritium. The irradiated burnable poison rods can then be removed from the fuel assemblies and shipped to another location (Savannah River Plant) for tritium extraction. The first phase of the tritium program that requires the involvement of NRC is a lead test assembly (LTA) demonstration. LTA irradiation would serve as a confirmatory test of the design for TPBARs that DOE has developed over the past 10 years.

DOE expects that LTAs will be available for irradiation in the core of a CLWR in late summer 1997. At the reactor involved in the LTA demonstration (Watts Bar, Unit 1), 32 target rods (8 each in 4 LTAs, with 1 LTA inserted in each quadrant of the core) will be irradiated for one fuel cycle.

The second phase of DOE's tritium production program that will require NRC review is DOE's submittal of a topical report for production irradiation in mid-1998. The staff will initiate review 
of that report concurrently with the irradiation of the LTAs and anticipates that it will document its review in a safety evaluation report to be issued in early 1999. DOE has stated that, because the primary purpose of the LTA demonstration is to build confidence among prospective licensees, completion of the LTA demonstration is not an essential precursor to submittal of the topical report. The NRC staff agrees that it could initiate review of the topical report independent of the LTA demonstration. However, the staff may need information from the LTA demonstration before it can complete its review of the production topical report. The NRC staff will send the Commission its safety evaluation on the production phase topical report before the staff issues its safety evaluation.

The third and final phase of DOE's tritium production program, which may require NRC's review is the actual production of tritium. Under one of the DOE options being considered, this review would be conducted, not at the request of DOE, but as a result of a request by a licensee for amendment of its facility operating license to authorize use of up to 3300 TPBARs in each core reload. A license amendment is required in order to make changes to the plant technical specifications and to address any unreviewed safety questions pertaining to such use. A request for a license amendment authorizing irradiation of burnable poison rods for production of tritium is expected to be received at the beginning of 2000. A request for a license amendment will be noticed in the Federal Register and will be the subject of an opportunity for hearing. If a hearing is requested, the Commission will be notified if the staff intends to make a "no significant hazards consideration" finding (which would allow the amendment to become effective before the conclusion of a hearing).

Regardless of which dual-path strategy is chosen, the first core loading of TPBARs will be fabricated during 2002 and 2003 as part of DOE's target demonstration program. Also, the licensing activities to support CLWR production of tritium will be completed. Should CLWR production be chosen, the TPBARs will be irradiated, cooled, and shipped in 2004 and 2005 to support the Presidential decision directive's requirement for production of the first tritium gas at Savannah River by the end of 2005 .

\section{SECY-96-212}

In SECY-96-212, the staff described DOE's proposal for the CLWR production of tritium and presented its approach for reviewing DOE's proposal under the terms of the joint MOU of May 22,1997 . The staff proposed to consider whether irradiation of LTAs containing TPBARs could be accomplished under the provisions of 10 CFR 50.59 without NRC licensing action.

In its staff requirements memorandum (SRM) of December 10, 1996, the Commission approved the staff's review approach. However, the Commission directed the staff to hold a series of public meetings to give the public an opportunity to comment on the technical issues during the LTA phase and to inform the public of the staff's activities early in the evaluation process. The initial meeting was held at NRC Headquarters on February 25, 1997. The next public meeting 
directed by the Commission is expected to be held in the vicinity of the LTA host facility selected by DOE (Watts Bar) in the summer of 1997, before the TPBAR LTAs are inserted into the reactor. Finally, the staff will hold similar local public meetings before TPBARs are inserted in any particular NRC-licensed facility for the production phase of DOE's CLWR tritium program.

DOE's report, as revised, contains sufficient information for the staff to determine whether the use of a CLWR to irradiate a limited number of TPBARs in LTAs raises generic issues involving an unreviewed safety question. The staff has reviewed the DOE report and has prepared this safety evaluation to address the acceptability of the proposed irradiation and whether a licensee can undertake irradiation of the LTAs under the provisions of 10 CFR 50.59 without NRC licensing action. This safety evaluation is being transmitted to the Commission before the safety evaluation is issued.

Independent of its review of the DOE report, the staff is conducting vendor-related activities with respect to quality assurance (QA) plans and fabrication inspections in order to give DOE insights on how the NRC will review the production phase report.

\subsection{Purpose}

As described in SECY-96-212, the original purpose of the DOE report was to provide sufficient information for the NRC staff to determine whether use of a CLWR to irradiate a limited number of TPBAR LTAs raised generic issues involving an unreviewed safety question. Should the staff determine that no generic unreviewed safety questions are involved in irradiating TPBAR LTAs in a CLWR, a licensee undertaking such irradiation would be permitted to proceed under the provisions of 10 CFR 50.59 without NRC licensing action, subject to plant-specific evaluations confirming that no unreviewed safety question exists and that no change in a technical specification is needed.

The original report addressed the issue of TPBAR LTA irradiation generically and presented several plant-specific analyses for an unspecified Plant A and Plant B. On February 7, 1997, DOE announced the selection of Watts Bar as the facility that would conduct the one-time confirmatory test of components that could be used in the production of tritium. After selecting Watts Bar as the facility that will carry out out the confirmatory TPBAR LTA irradiation, and in response to the staff's requests for additional information, DOE submitted a revised report. The revised report no longer addresses the TPBAR LTA irradiation in generic terms, but presents analyses and data based solely on the Watts Bar facility. For that reason, the staff shifted the focus of its review from a generic evaluation of potential unreviewed safety questions to a more specific evaluation addressing TPBAR LTA irradiation at Watts Bar.

The staff's review of the DOE report and the staff's conclusions regarding the applicability of the provisions of 10 CFR Part 50.59 in implementing the proposed TPBAR LTA irradiation are 
documented in this safety evaluation.

\subsection{Scope}

The staff has evaluated DOE's report, submitted by letter dated December 4, 1996, and revised by letter dated March 17, 1997. The staff has also considered information submitted by DOE in letters of February 7 and 14, 1997, and March 7 and 12, 1997. These letters responded to the staff's requests for additional information dated January 3 and 13, 1997 and to the staff's letters of February 4 and 24, 1997, providing guidance on benchmarking for the VIPRE amd PHOENIX codes. The staff has also reviewed classified versions of the DOE report that were submitted by letters dated December 4, 1996, and March 3, 1997, containing confidential restricted data. None of the information in this safety evaluation is classified.

\subsection{Organization of This Safety Evaluation}

The format of this safety evaluation follows that of the DOE report (PNNL-11419) as closely as possible. The staff has added Section 10 to summarize the results of its review. Section 10 of this safety evaluation also summarizes the remaining plant-specific issues that will have to be addressed in the TeNnessee Valley Authority's application for an amendment to the facility operating license for Watts Bar to permit TPBAR LTA irradiation. 


\section{TRITIUM-PRODUCING BURNABLE ABSORBER ROD LEAD TEST ASSEMBLY DESIGN}

In Chapter 2 of its report, the Department of Energy (DOE) describes (1) the mechanical design of the tritium-producing burnable absorber rod (TPBAR) lead test assembly (LTA) and its acceptability, (2) the surveillance program, and (3) the testing and inspection program.

\subsection{LTA Design Description}

In Section 2.1 of its report, DOE describes the design features, materials, and operation of the TPBAR. The TPBAR LTA is designed to meet the operating requirements of a large four-loop Westinghouse reactor under Condition I, II, III, and IV events, ${ }^{1}$ as defined in the Watts Bar Final Safety Analysis Report.

The LTA consists of a Westinghouse hold-down assembly with 8 TPBARs and 16 thimble plugs as shown in Figure 2-1 of the DOE report. The TPBAR will be inserted into a fresh $17 \times 17$ Westinghouse standard fuel assembly that has no control rod assembly. The external dimensions of the TPBAR are similar to those of the standard Westinghouse burnable poison rod assembly (BPRA). Design characteristics of the TPBAR, the conventional BPRA, and wet annular burnable assemblies (WABAs) are compared in Table 2-1 of the DOE report: the TPBAR is dimensionally similar to both the BPRA and the WABA. Because the TPBARs are installed in the standard Westinghouse guide thimble, the diameter of TPBARs is similar to that of the BPRA and the WABA. Because of the length of the absorber's poison (142 in.) $(360.7 \mathrm{~cm})$ and overall length of the rods $(152.35 \mathrm{in}$.) $(387 \mathrm{~cm})$, the TPBAR is physically more similar to the BPRA (rod length $=152.59$ in. [387.6 cm], poison $=142 \mathrm{in}$.) than the WABA (rod length $=$ 149.83 in. [ $380.6 \mathrm{~cm}]$, poison $=134 \mathrm{in} .[340 \mathrm{~cm}])$. The dimensions listed in Table 4-1 of the DOE report vary slightly from the dimensions presented in Table 2-1 of the DOE report.

On the basis of the comparison of dimensions between the TPBAR and the conventional BPRA and the use of standard Westinghouse design components for the LTA hold-down assemblies, the staff concludes that TPBARs are similar in form to BPRAs. The staff's evaluation as to whether the TPBAR is similar in function to the BPRA is in Sections 3 and 4 of this safety evaluation, which relate to the nuclear and thermal-hydraulic design of TPBARs.

The LTA is designed for a large four-loop Westinghouse pressurized-water reactor (PWR) and is compatible with the fuel assembly, reactor vessel internals, reactor coolant chemistry, refueling

\footnotetext{
${ }^{1}$ Condition I = normal operation and operational transients; Condition II = faults of moderate frequency; Condition III = infrequent faults; Condition IV = limiting faults
} 
system and tools, and spent fuel storage facility. The LTA is a removable reactor core component, installed inside a fuel assembly that has no reactor control rod assembly.

The TPBAR LTA design consists of subcomponents clad with American Iron and Steel Institute (AISI) Type 316 stainless steel (316 SS). The 316 SS tubular cladding gives structural strength and acts as the pressure barrier between the TPBAR internals and the reactor coolant system (RCS). The inner surface of the cladding is coated with a permeation-resistant aluminum barrier. The TPBAR internals consist of a plenum subassembly, 12 pencils, and a lower getter disk. A pencil consists of a Zircaloy-4 liner tube surrounded by absorber pellets. The liner and absorber pellets are contained in a getter tube. The getter tube is made from nickel-plated Zircaloy-4 (NPZ). The nickel plating maintains the getter effectiveness by preventing oxidation of the Zircaloy-4; the oxide film would become a permeation-resistant film.

The Zircaloy -4 liner inside the absorber pellets scavenges free oxygen and water vapor by reacting to form an oxide on its surface. The reaction of the tritiated water vapor with the liner releases tritium, which is then absorbed by the getter. The liner also provides mechanical support to keep the absorber pellets from relocating.

The upper getter disk and an attached getter tube house a stainless steel plenum spring located above the top pencil in the cladding tube. This subassembly provides an axial force to restrain the pencils during handling and shipping operations and allows for axial growth of the pencils caused by irradiation, hydriding, and thermal growth of the pencils while in the reactor. The upper disk subassembly and the lower getter disk maintain low tritium partial pressure at the ends of the TPBAR to minimize tritium leakage through uncoated weld preparation zones of the cladding and end plugs.

The TPBAR is sealed using a 316 SS top plug and a 316 SS bottom plug welded to the cladding tube. Before the final closure is welded shut, the TPBAR is evacuated and repressurized to 1 atmosphere with helium.

\subsection{Mechanical Design Evaluation}

In Section 2.2 of its report, DOE has established and evaluated a number of criteria for the TPBAR. DOE has specified that swelling or shrinking of internal TPBAR components must be accommodated by the TPBAR design. On the basis of the specified tolerances and clearances, and considering the extensive documentation of the selected materials behavior in the reactor environment, DOE states that the design adequately addresses swelling and shrinking of the TPBAR components for the design irradiation lifetime. The swelling and shrinking of each TPBAR component is discussed in the sections that follow. 


\subsubsection{Cladding and Top and Bottom End Plugs}

Section 2.2.1 of DOE's report states that the structural integrity of the TPBAR will be maintained during Conditions I through IV, and throughout shipping and handling, with the exception of the large-break loss-of-coolant accident (LBLOCA). The cladding, end plugs, and associated welds form the pressure boundary of the TPBAR. The integrity of this pressure boundary during Condition I, II, III, and IV events is discussed next.

\section{Stress-Strain}

In Section 2.2.1.1 of its report, DOE states that the TPBAR cladding stresses and the end plug weld stresses will not result in cladding collapse, excess ovality, or cracking over the irradiation life of the TPBAR. The structural members (cladding and top and bottom end plugs) of the LTA were designed using stress and fatigue criteria and methodology consistent with the American Society of Mechanical Engineers (ASME) Boiler and Pressure Vessel Code (ASME Code, Section III, Division I, Subsection NG, Article 3220, 1995.) The external pressure criteria of the code were excluded because the LTA is not a reactor core structural component. Also, strength values used to calculate the TPBAR stresses are based on materials data because the material properties of American Society of Testing and Materials Standard A771 Type 316 stainless steel (ASTM A $771316 \mathrm{SS}$ ) are not included in the code. The stress correlation shown in the DOE report is used to evaluate the discontinuity stress at the weld junction between the cladding and end plug.

DOE states that the highest loads on the BPRA or TPBAR are caused by worst-case operating pressures or by handling and shipping loads. Handling and shipping loads exceed the loads encountered during seismic events. Therefore, operating-basis earthquake (OBE) and safeshutdown earthquake (SSE) loads were not analyzed in the cladding stress analysis and are bounded by the loads analyzed by DOE.

DOE has analyzed the cladding for the most conservative pressure, temperature, and dimensional tolerances for Conditions I, II, III, and IV. For each design condition, the internal design pressure was assumed to be the worst case internal pressure (accounting for non-ideal gas behavior) at the temperature of concern. The factor of safety for each design condition exceeds the requirements of the ASME Code.

DOE states that the results indicate that, except for the LBLOCA (where the TPBARs are assumed to fail), the lowest factor of safety based on yield strength is during the hydrostatic test at 1.25 times the reactor design pressure. Stress analyses of the TPBAR produced the following results:

- Critical buckling pressures were verified by experiment to be greater than the RCS design pressure and temperature of $2500 \mathrm{psia}(17.2 \mathrm{MPa})$ and $660^{\circ} \mathrm{F}\left(347^{\circ} \mathrm{C}\right)$. The lowest 
factor of safety based on pressure is 2.3 (critical buckling pressure divided by the measured pressure).

- The TPBAR was designed to prevent collapse or excess ovality from the effects of pressure, external temperature, and irradiation-induced creep.

- The TPBAR was designed not to collapse under hydrostatic pressure test conditions.

- A pressurized TPBAR was designed to withstand a 4-g axial and a 6-g lateral shipping and handling load at the end of life (external pressure of $14.7 \mathrm{psia}[0.1 \mathrm{MPa}]$ and internal pressure of $1420 \mathrm{psia}[9.8 \mathrm{MPa}]$ at $72{ }^{\circ} \mathrm{F}\left[22^{\circ} \mathrm{C}\right]$ ), with a factor of safety of 4.9 .

On the basis of cladding stress calculations, DOE states that cladding breach is not expected during a small-break loss-of-coolant accident (SBLOCA). However, because high cladding pressures occur at elevated temperatures during an LBLOCA, it is likely that the TPBAR cladding would fail under postulated accident conditions. Burst testing of specimens indicates that the cladding will burst at about $1500^{\circ} \mathrm{F}\left(815.5^{\circ} \mathrm{C}\right)$ and $5230 \mathrm{psia}(36.1 \mathrm{MPa})$, compared to a predicted LBLOCA temperature of $2200^{\circ} \mathrm{F}\left(1204^{\circ} \mathrm{C}\right)$ with a differential pressure across the cladding that would exceed $5230 \mathrm{psia}(36.1 \mathrm{MPa})$. Chapter 6 of the DOE report assesses the effects of a TPBAR rupture.

DOE states that cold-worked (CW) $316 \mathrm{SS}$ cladding is stable at the irradiation temperatures and neutron fluence encountered during the in-core residence period for the TPBAR, $650{ }^{\circ} \mathrm{F}(343$ $\left.{ }^{\circ} \mathrm{C}\right)$ and $5 \times 10^{21} \mathrm{n} / \mathrm{cm}^{2}(\mathrm{E}>1 \mathrm{MeV})$. The irradiation creep and volumetric swelling strains are less than 2 percent. Nominal changes in cladding diametric dimensions due to irradiation creep are plotted in Figure 2-4 of the DOE report and are less than 0.0004 in. $(10.2 \mu \mathrm{m})$. This is much less than the design limit on cladding strain of 1 percent.

The staff concludes that the method used to analyze the stresses on structural members is conservative as long as the margins specified in Subsection NG of Section III of the ASME Code are satisfied. However, DOE used the 1995 edition of the code, but the staff has only endorsed the 1989 edition. (A comparison of Article NG-3220 in the 1995 edition with Article NG-3220 in the 1989 edition indicates that they are identical.) A licensee that uses this analysis must submit a relief request to use the later edition.

The staff further concludes that reliance on ASTM A 771 for the purchase of the cladding does not satisfy the requirements of 10 CFR Part 50, Appendix B. The quality assurance (QA) program described in ASTM A 771 needs to be supplemented to include conformance with NQA-1 and 10 CFR Part 50, Appendix B.

DOE's analysis provides reasonable assurance that the cladding and top and bottom end plugs are designed consistent with the ASME Code for both static and fatigue loads. DOE's conclusion that the OBE and SSE loads need not be analyzed since the worst-case pressures and handling and shipping loads exceed the loads induced by the OBE and by the SSE is acceptable. 
TPBAR LTA DESIGN

DOE's analysis, experimental data, and operating experience offer reasonable assurance that the cladding will not be affected for Conditions I, II, and III. DOE's experimental data indicate that the cladding is expected to fail during an LBLOCA (Condition IV). On the basis of the design of the Westinghouse four-loop reactor, the fuel bundles and TPBAR cladding temperature could reach $2200^{\circ} \mathrm{F}\left(1204^{\circ} \mathrm{C}\right)$ during a postulated LBLOCA, much higher than the temperature at which the cladding is expected to fail. The consequences of the cladding failure are discussed in detail in Section 6.3.3 of this safety evaluation.

\section{Cladding Collapse}

In Section 2.2.1.2 of its report, DOE states that the cladding will be free- standing and will not collapse as a result of external pressure or creep for a design life of 550 effective full-power days (EFPDs), corresponding to an 18-month fuel cycle. DOE describes external pressure tests of barrier-coated cladding in Chapter 5 of its report. DOE states that these tests demonstrate that the cladding is strong enough to resist mechanical buckling from the reactor coolant pressure. DOE also states that the calculated change in ovality of a TPBAR as a function of time, neutron flux, and uniform external pressure caused by cladding creep shows that the TPBAR cladding resists collapse through creep buckling.

On the basis of its review of Section 2.2.1.2 of DOE's report, the staff concludes that DOE has demonstrated through analysis of experimental data that the design factors of safety for Subsection NG are met. This, along with DOE's operating experience, gives adequate assurance that the cladding will remain free-standing and will not collapse because of external pressure or creep for the design life.

\section{Vibration Fatigue, Design Cycle Fatigue, and Fretting Wear}

Section 2.2.1.3 of DOE's report states that neither the TPBAR nor its associated guide thimble will fail because of vibration fatigue, design cycle fatigue, or fretting wear resulting from reactor coolant flow-induced vibration. Reactor coolant flowing axially through the annulus between the TPBAR and the fuel assembly guide thimble imposes bending stresses that cause the TPBAR to vibrate. The maximum credible vibration stress was calculated to be an alternating stress that is bounded by the gap between the TPBAR and the guide thimble. This stress is significantly less than the endurance limit of 24,000 psi (165.5 MPa) specified by the ASME Code and, therefore, the number of cycles a TPBAR may be subjected to without failure is well in excess of $1 \times 10^{11}$. To exceed $1 \times 10^{11}$ cycles during an 18 month fuel cycle (550 EFPDs) would require the TPBAR to oscillate at $2100 \mathrm{~Hz}$. Tests have shown that a BPRA constrained within a guide thimble oscillates at less than $1 \mathrm{~Hz}$. A TPBAR and BPRA are dimensionally the same and are similar in weight and stiffness, and should exhibit similar frequencies of oscillation. BPRAs used in PWRs have not experienced failure from vibration fatigue. Therefore, the staff concludes that failure of a TPBAR as a result of vibration fatigue is not plausible. 
Flow-induced vibration of a TPBAR within a guide thimble could cause the contacting surfaces to wear. The TPBAR and a BPRA are dimensionally similar and are similarly constrained by the guide thimble while vibrating. DOE states that experience and available test data for BPRAs, including austenitic SS clad BPRAs, have shown the wear to be acceptable. The similarity in resistance to wear of 304 SS and 316 SS further ensures that the wear for the LTA will be acceptably small. DOE's conclusions are consistent with the absence of BPRA failures by these mechanisms. The cladding was evaluated for design cycle fatigue failure caused by changes in pressure and temperature during the reactor duty cycle, using the ASME Code. The staff concludes that, as long as the cladding satisfies the conditions of Article NG-3222.4(d), it will have the ability to withstand the cyclic service, and an analysis in accordance with Article NG3222.4(d) is not required. The design cycle fatigue evaluation is based on the transient conditions and design cycles for Watts Bar, shown in Table 2-5 of the DOE report.

On the basis of its review of Section 2.2.1.3 of DOE's report, the staff concludes that DOE has provided reasonable assurance that the TPBARs will not fail as a result of such flow-induced effects as vibration fatigue, design cycle fatigue, or fretting wear based on calculated frequencies of vibration, previous experience with burnable poison assemblies, and previous experience with stainless steel cladding. This conclusion is supported by actual operating experience with stainless steel cladding on fuel assemblies in several plants, including the Consumers Power Company's Palisades plant.

\section{Chemical Properties of the Cladding}

Section 2.2.1.4 of DOE's report states that corrosion and erosion of the TPBAR outer surface will not cause material transfer into the reactor coolant in excess of rates applicable to other reactor internal components. The cladding is resistant to chemical attack from the chemical species normally present in the reactor coolant. Because $316 \mathrm{SS}$ has not been extensively used for corrosion studies, data for the uniform corrosion of $304 \mathrm{SS}$ were used to estimate the cladding wastage from corrosion by the reactor coolant. Based on the corrosion rates for 304 SS in PWRs and in the Engineering Test Reactor (ETR), DOE estimates that the corrosion rate for the TPBAR $316 \mathrm{SS}$ cladding is less than 0.0001 in. $(2.5 \mu \mathrm{m})$ per year. A conservative value of $0.0003 \mathrm{in} .(7.6 \mu \mathrm{m})$ for an 18 -month fuel cycle (550 EFPDs) was applied to the TPBAR. As discussed in Section 5 of this safety evaluation, $316 \mathrm{SS}$ is more corrosion - resistant than 304 SS. Consequently, the wastage estimate used in the design evaluation is conservative for $316 \mathrm{SS}$. TPBARs are designed to be free of crevices; therefore, crevice corrosion is of no concern.

Stress corrosion cracking (SCC) in 300-series stainless steel requires sensitization, an aggressive environment, and high stresses; it may be aggravated by neutron fluences, hydrogen, and high temperatures. DOE states that the formation of oxidizing species is effectively suppressed in PWR coolant. Austenitic stainless steel is not susceptible to SCC in PWR coolant, because of the low oxygen concentration (less than $100 \mathrm{ppb}$ ). SSC is discussed in more detail in Section 5 of this safety evaluation. No significant chemical reaction is expected between the $316 \mathrm{SS}$ TPBAR cladding or end plugs and the reactor coolant. DOE states that experience with SS-clad 
fuel and BPRAs in PWRs indicates that, given the current PWR water chemistry, crud deposition is acceptably low.

Experience shows that erosion of austenitic SS clad BPRAs is insignificant. The wear resistance of 316 SS further ensures that the erosion of the LTAs will be acceptably small.

The staff concludes that DOE has presented operating and experimental data, which provide reasonable assurance that austenitic stainless steels, including $316 \mathrm{SS}$, are resistant to SCC in PWR environments. This is particularly true of the cladding of TPBARs that are only exposed to one operating cycle. There is also considerable evidence that austenitic stainless steels are highly resistant to erosion. The cladding on the reactor vessels of PWRs and the piping for the primary loop are constructed using austenitic stainless steels. High corrosion rates have not been observed, nor has erosion corrosion been reported in the piping or on the cladding. Also, stress corrosion cracking has not been reported for these materials in PWR environments.

\subsubsection{Absorber Pellets}

The thermal and physical properties of absorber pellets are summarized in Chapter 5 of the DOE report. In Section 2.2.2 of its report, DOE states that structural integrity of absorber pellets will be maintained while producing tritium. The next two sections address the chemical properties and the stability of the absorber pellet. These discussions lead to the conclusion that the structural integrity of absorber pellets is acceptable except for localized structural damage at the breach site during a postulated LBLOCA, and will be maintained during all Condition I, II, III, and IV events.

\section{Chemical Properties of the Absorber Pellets}

In Section 2.2.2.1 of its report, DOE states that the absorber pellets do not react with the TPBAR components. In the event of a cladding breach, water ingress would dissolve a microscopic layer of lithium from the surface of absorber pellets; otherwise, the absorber pellets are insoluble in the coolant water. Lithium is produced by irradiation of boron; hence, it is always present in the primary system. The small additional amount of lithium that might be introduced into the primary system as a result of cladding breach is expected to have little effect on materials in contact with the primary coolant.

\section{Stability of the Absorber Pellets}

In Section 2.2.2.2 of its report, DOE states that the strength of the absorber pellets enables them to resist fracture during TPBAR handling and to resist cracking from substantial thermal cycling during reactor operations. Thermal expansion and swelling for absorber pellets are described in the Materials Property Handbook (MPH). Lithium aluminate is a high-temperature ceramic material that is very stable at elevated temperatures. Thermal expansion and swelling strains are accommodated by the TPBAR design. No densification or significant phase change of the 
absorber pellets is predicted over the range of temperatures encountered during Conditions I through IV.

Experience with irradiation of absorber pellets has shown excellent stability up to a gas volume ratio (GVR) of 239, based on theoretical pellet density, or $216 \mathrm{GVR}$, based on actual pellet density given in the DOE report. As discussed in Section 5 of the safety evaluation, absorber pellets were irradiated in the Advanced Test Reactor (ATR) to 239 GVR with only minor microcracking that had no effect on the structural integrity of the pellets. Absorber pellet disintegration, major cracking, and relocation is not expected below the design goal of $215 \mathrm{GVR}$. As indicated in Table 2-6 of the DOE report, the maximum calculated GVR is 209 . The average GVR is 174 .

The staff concludes that DOE has presented analysis and operating experience that gives reasonable assurance that the absorber pellets will maintain integrity during tritium production.

\subsubsection{Getters and Liners}

The thermal and physical properties of the getters and liners are discussed in Chapter 5 of the DOE report. Section 2.2.3 of the DOE report addresses the chemical and mechanical aspects of TPBAR design.

\section{Chemical Properties of the Getters and Liners}

In Section 2.2.3.1 of its report, DOE states that the getters and liners do not react with the other TPBAR components. DOE states that the Zircaloy-4 getter and liner are insoluble in the reactor coolant

\section{Stability of the Getters and Liners}

In Section 2.2.3.2 of its report, DOE states that dimensional changes in Zircaloy-4 getters and liners are caused by thermal expansion, irradiation growth, and hydride-induced swelling. DOE states that the irradiation growth of the Zircaloy-4 getters and liners at end of life (EOL) is less than 0.5 percent; therefore, the irradiation stability of the getter materials is acceptable. Hydriding cannot deform the cladding or the pellets because the hydrided getter is brittle and weaker than the cladding and pellets. The TPBAR dimensional design accommodates this growth and the swelling from hydriding.

The staff concludes that DOE has presented presented sufficient operating experience in an environment comparable to a PWR primary coolant to give reasonable assurance that the Zircaloy-4 getter and liner materials will experience no problems for the TPBAR design life of one cycle. 


\subsubsection{Plenum Spring}

Section 2.2.4 of the DOE report states that the plenum spring will have sufficient preload and spring rate to prevent movement of the pencil column stack during fabrication, shipping and handling, considering a 4-g axial acceleration loading at beginning of life (BOL). DOE states that the spring is made from $302 \mathrm{SS}$ and is similar in design to springs used in BPRA rods and fuel rods. The spring load stress has been established to be less than 60 percent of the yield stress, providing a safety factor of 1.66 after consideration has been given to tolerance stackup, internal and external pressure, thermal and radiation growth, compressed height of the spring, and pencil buckling. On the basis of a conservative safety margin and satisfactory commercial reactor experience with the material in this application, the spring is expected to provide the bearing load required for shipping and handling. No credit is taken for the spring in operational or reactor accident analysis.

\section{Chemical Properties of the Plenum Spring}

Section 2.2.4.1 of the DOE report states that the plenum spring is constructed of $302 \mathrm{SS}$ and does not react with the other TPBAR components. The spring is only slightly soluble in the reactor coolant. In the event of a cladding breach, a very small quantity of SS would dissolve in the reactor coolant.

\section{Stability of the Plenum Spring}

Section 2.2.4.2 of the DOE report states that the dimensional changes in the plenum spring result from thermal expansion and irradiation growth. These phenomena are described in Chapter 5 of the DOE report.

The staff concludes that $302 \mathrm{SS}$ is a high carbon stainless steel. The higher carbon content produces a higher yield and greater tensile strength, but a lower resistance to intergranular stress corrosion cracking (IGSCC). However, the 302 SS plenum spring is normally not in contact with the primary coolant because it is located within the sealed getter. Further, the PWR environment is not expected to cause SCC even if the primary solution comes in contact with the spring for part of one operating cycle.

\subsubsection{TPBAR Analytical Models}

Section 2.2.5 of the DOE report summarizes the analytical models used to calculate TPBAR operating temperatures, rod internal total pressure, pellet tritium release, gettering (process of chemically binding the tritium in hydrided form), and resulting tritium partial pressure.

The software used to calculate the TPBAR performance parameters is MATHCAD by Mathsoft Corporation. MATHCAD is an interactive spreadsheet, which permits calculations to be displayed and annotated, and which displays the results in an ongoing logical stream. In this 
way, axial peak values, such as peak getter loading and peak tritium release, can be identified.

The modeling in MATHCAD is based on ex-reactor gettering rates and cladding permeation data, and is supported by some additional burnable absorber test data. DOE states that the models may contain large uncertainties for some situations. The uncertainty in modeling test rods for some phenomena is, therefore, relatively large. These uncertainties are accommodated

in the conservatism of the TPBAR design. The MATHCAD model will be updated whenever post-irradiation examination (PIE) data become available.

DOE will need to submit additional documentation to show that the MATHCAD model is conservative, since DOE points out that the uncertainty in modeling some phenomena is relatively large. This documentation could consist of results obtained for other applications using MATHCAD and compared with actual operating service.

\section{TPBAR Component Operating Temperatures}

Section 2.2.5.1 of the DOE report states that heat is generated in the TPBAR from two sources: the ${ }^{6} \mathrm{Li}[\mathrm{n}, \alpha]^{3} \mathrm{H}$ reaction in the absorber pellets, which produces $4.8 \mathrm{MeV}$ of energy per disintegration, and gamma heating in the cladding, getter, liner, and the pellets. The heating from hydriding of the liner is negligible.

The TPBARs reside in guide thimbles within the fuel assembly, and are cooled by reactor coolant that flows up the annulus between the TPBAR and the guide thimble. The coolant in the annulus is heated slightly by the TPBAR, but gains significantly more heat from the guide thimble, which is heated by gamma radiation and heat transfer from the coolant outside the guide thimble. The coolant temperature rises from $559^{\circ} \mathrm{F}\left(293^{\circ} \mathrm{C}\right)$ at the bottom of the TPBAR to $620^{\circ} \mathrm{F}\left(327^{\circ} \mathrm{C}\right)$ at the top of the TPBAR.

\section{Calculation of TPBAR Internal Pressure}

Section 2.2.5.2 of the DOE report states that the internal pressure of the TPBAR is determined by the internal gas concentration and the gas temperature. Essentially all of the tritium generated in the TPBAR is absorbed by the getter and liner; therefore, the internal pressure is due to the helium generated in the TPBAR. The generation of helium in the absorber pellet results from the ${ }^{6} \mathrm{Li}[\mathrm{n}, \alpha]^{3} \mathrm{H}$ reaction and can be equated to the ${ }^{6} \mathrm{Li}$ depletion. The limiting design criterion for the internal gas pressure at $675^{\circ} \mathrm{F}\left(357^{\circ} \mathrm{C}\right)$ is $3000 \mathrm{psia}(20.7 \mathrm{MPa})$.

The staff has reviewed Section 2.2.5 of the DOE report and concludes that DOE must present additional information to confirm that the MATHCAD analytical model is conservative when it is used to calculate TPBAR temperatures and pressures. 


\subsubsection{TPBAR Performance}

\section{TPBAR Bowing Caused by Thermal Effects, Radiation, Coolant Flow, and Creep}

Section 2.2.6.1 of the DOE report states that the TPBAR must be sufficiently straight to allow insertion into a fuel assembly and must maintain dimensional integrity to allow removal from an irradiated fuel assembly without excessive force. DOE states that significant bowing of the TPBAR is precluded by the uniformity of its circumferential temperatures during irradiation, combined with the very small thermal creep, irradiation-induced creep, and swelling strains under the low stresses, temperatures, and neutron fluences encountered. TPBARs are restrained by the guide thimble so that the bowing is limited to what is permitted by the width of the annular region between the outer surface of the TPBAR and the inner surface of the guide thimble. This amount of bowing is accommodated by the TPBAR design without damaging the components. Analyses were performed to verify that the changes in internal component dimensions resulting from thermal, irradiation, coolant flow, and creep effects did not cause interferences between components. On the basis of BPRA experience and the analysis of TPBAR bowing, the thermal, irradiation, coolant flow, and creep effects are small enough not to inhibit the insertion of an LTA into an unirradiated fuel assembly or the removal of an LTA from an irradiated fuel assembly.

The flow through a guide thimble containing a BPRA or a TPBAR is a function of the guide thimble and rod cross-sectional areas. The external dimensions of the TPBAR are similar to those of a BPRA; therefore, guide thimbles containing either a TPBAR or a BPRA will have similar flow rates. Dimensional changes throughout the fuel cycle have an insignificant impact on flows. Therefore, the contribution to bowing of the TPBAR by reactor coolant flow is considered negligible, considering the structural strength of the TPBAR.

\section{Compatibility of the TPBAR Internal and Cladding Materials}

In Section 2.2.6.2 of its report, DOE states that the TPBAR components are mechanically, chemically, and metallurgically compatible during PWR irradiation conditions. Metallurgical liquidus interactions between components do not occur below $1760^{\circ} \mathrm{F}\left(960^{\circ} \mathrm{C}\right)$. Melting of the getter was not detected below $1832^{\circ} \mathrm{F}\left(1000^{\circ} \mathrm{C}\right)$ during transient heating tests. Specific melting temperatures for TPBAR component materials are presented in the MPH. The absorber pellet melting temperature of $3182^{\circ} \mathrm{F}\left(1750^{\circ} \mathrm{C}\right)$ exceeds all anticipated and design-basis temperatures.

The Advisory Committee on Reactor Safeguards (ACRS) questioned this DOE conclusion at DOE's March 7, 1997, presentation to the ACRS. The ACRS requested DOE to submit additional evidence to support the conclusion. ACRS has also requested information on thermal compatibility of coatings on the cladding, metal-metal interactions, and intermetallic interactions during design-basis accidents.

ACRS provided a preliminary assessment dated March 17, 1997, of the metal-metal interactions and intermetallic interactions during design basis accidents and concluded that the temperatures would not be high enough so that metal-metal or intermetallic interactions would be possible. 
The staff likewise concluded that the temperatures would be too low to initiate any of these interactions based on examination of relevant phase diagrams. Nevertheless, DOE has agreed to respond to the ACRS questions. The staff will review this information following its submittal by DOE.

\section{Water-Logging Rupture}

As a result of experience with an irradiation of an iridium capsule at the Oak Ridge High Flux Isotope Reactor (HFIR), the staff asked DOE to prepare an analysis of the potential for water logging rupture of a TPBAR. DOE has provided its analysis in Section 2.2.6.3 of its report.

\section{- Potential for Chemical Interaction}

Chemical reactions internal to the TPBAR include burnup-induced release of tritium and moisture from the lithium aluminate absorber pellets, oxidation of the liner, and hydriding of the getters. The TPBAR design requires that these reactions be limited to minimize internal pressurization with tritium gas and steam.

Oxidation of the 316 SS cladding by the PWR coolant is discussed in Section 2.2.1.4 of the DOE report. Oxidation of the coated inner surface of the cladding is limited by the quantity of oxygen and moisture released from the lithium aluminate absorber pellets and remaining after reaction with the Zircaloy-4 liner.

Breach of the TPBAR cladding is unlikely. In the event that a TPBAR is breached, water is expected to partially dissolve the aluminide barrier, releasing insignificant amounts of $\mathrm{Al}_{2} \mathrm{O}_{3}$, water-soluble $\mathrm{AlCl}_{3}$, and other barrier constituents. Lithium aluminate is insoluble in water. A microscopic layer of lithium may be leached from the surface of the absorber pellets. However, given the high density and stability of the absorber pellets, and the fact that they are contained within a getter tube within the cladding, the possibility of pellet dissolution is extremely remote.

In the event of a sudden temperature transient with a water-logged TPBAR, the low level of heat generation in the TPBAR would cause pressure changes to be sufficiently slow to allow the internal TPBAR pressure to equalize with the RCS pressure without further cladding damage or ejection of internal material. Also, the water would not boil because of the low heat generation and the increase in heat transfer caused by the replacement of helium inside the TPBAR with water. Radiological consequences associated with a postulated breached TPBAR are presented in Chapter 6 of the DOE report.

- Water-Logged TPBAR in Dry Cask Storage

If a water-logged TPBAR is placed in dry cask storage, there is a potential for an increase in TPBAR temperature and pressure as a result of internal heat generation of the TPBAR. 
A concern is that the water in the TPBAR could boil and cause overpressurization. However, the TPBAR generates less than $3 \mathrm{~W}$ of heat 150 hours after shutdown. An analysis of the TPBAR stored in a dry cask shows that the maximum temperature increase of the TPBAR due to internal heat generation is less than $3{ }^{\circ} \mathrm{F}$ and boiling will not occur in the TPBAR.

\section{Mechanical Interaction Between Absorber Pellets and Cladding}

In Section 2.2.6.4 of its report, DOE states that pellet-cladding interactions do not occur in the TPBAR because: (1) cladding creepdown is insufficient to close the gap between the cladding and the getter, (2) the getter encloses the pellets and thereby restricts pellet movement, (3) the annular pellets surround the liner, which further restricts the movement of the pellets, (4) the pellets are dimensionally stable, and (5) design clearances were selected to ensure that interference does not occur.

\section{Failure and Burnup Experience}

In Section 2.2.6.5 of its report, DOE states that a review of the failure and burnup experience during testing of absorber pellets and tritium target test rods is provided in Tables 2-5 and 2-6. No failures were observed.

\section{TPBAR Component and Cladding Temperatures}

In Section 2.2.6.6 of its report, DOE states that TPBAR component and cladding temperatures are compatible with the operating environment of Watts Bar.

\section{Potential Effect of Sudden Temperature Transients}

In Section 2.2.6.7 of its report, DOE states that sudden temperature changes during startup, shutdown, or power spikes do not cause significant thermal or differential thermal expansion stresses, because the TPBAR component walls are thin and the component thermal time constants are much less than the duration of the transient.

On the basis of DOE's calculations, test results, and past experience in DOE operating facilities, the staff concludes that DOE has provided reasonable assurance that the TPBAR components are mechanically, chemically, and metallurgically compatible during PWR irradiation conditions. In addition, the commercial nuclear industry has operating experience with austenitic stainless steel cladding in PWR environments at several plants, including Consumers Power Company's Palisades plant, and has not experienced problems with the stainless steel cladding after several years of service. There is also considerable operating experience with austenitic stainless steel reactor vessel cladding and austenitic stainless steel piping in PWR environments that indicates that austenitic stainless steel components are compatible with these environments. 


\subsection{Surveillance Program}

In section 2.3 of its report, DOE states that an LTA surveillance program is not planned since the LTAs will only be irradiated for one cycle. Additionally, the current monitoring program at

Watts Bar should be able to identify anomalies if they were to occur. The staff believes that the Watts Bar surveillance program should be adequate for one cycle of operation with TPBAR LTAs installed in the core.

\subsection{Testing and Inspection Plan}

In Section 2.4 of its report, DOE states that no special testing or monitoring program is necessary. Standard start-up tests, flux mapping, and power monitoring will be performed in conjunction with Watts Bar's operating procedures.

In Section 2.4.4 of its report, DOE discusses the visual examination of the TPBAR LTAs after their removal from the core. The visual examination will be for obvious damage to TPBARs, which would then require special handling procedures.

\subsection{Conclusions}

The staff has reviewed the design of the TPBAR and has concluded that as long as the stresses on structural members meet the margins specified in Subsection NG of Section III of the ASME Code, the design will be conservative. DOE has presented sufficient analyses, test data, and operating experience data to give reasonable assurance that the TPBARs will be compatible with the environment in the core of a PWR. In addition, there is a large amount of operating data incore and in the primary coolant system that indicates that austenitic stainless steels are compatible with PWR environments.

DOE presented experimental data and analyses which indicate that TPBAR cladding integrity will be maintained during Condition I, II, and III. The cladding will likely be breached during an LBLOCA at Condition IV. The consequences of this breach are discussed in Section 6.4 .3 of this safety evaluation.

During its review of Chapter 2 of the DOE report, the staff identified a number of areas in which the Tennessee Valley Authority will have to present additional analyses as part of its application for an amendment to the facility operating license for Watts Bar before the staff can reach a conclusion of acceptability. These include the following:

(1) DOE has not addressed the use of the 1995 Edition of the ASME Code. A relief request will be required by the host plant for the use of the 1995 code since the NRC staff has only endorsed up to the 1989 Edition of the ASME Code.

(2) DOE has not addressed the conformance of the design with 10 CFR Part 50, Appendix B and NQA-1 because the cladding was ordered to conform to ASTM A 771. This will have to be resolved before the TPBARs can be loaded into a PWR core.

(3) DOE has not addressed the issues of the effect of thermal cycling on the components of the TPBAR and metal-metal and intermetallic interactions during a design-basis accident. 
(4) DOE will need to present additional documentation to show that the MATHCAD analytical model is conservative when it is used to calculate TPBAR temperatures and pressures. 


\section{NUCLEAR DESIGN DESCRIPTION}

In Chapter 3 of its report, the Department of Energy (DOE) discusses the effects of the tritiumproducing burnable absorber rod (TPBAR) lead test assemblies (LTAs) in terms of nuclear design, power distribution, reactivity control, and reload safety analysis. Since the TPBARs will replace some of the burnable poison rods in the reload core, DOE proposes to demonstrate through scoping analyses that the TPBAR is similar in nuclear characteristics to burnable poison rod assemblies (BPRAs) and will satisfy the same nuclear design requirements. DOE states that the nuclear design criteria will be assessed in the core reload evaluation using NRC-approved methodologies. This chapter investigates whether the TPBARs have nuclear properties similar to BPRAs and wet annular burnable assemblies (WABAs) and whether the lithium-based absorbers have any sensitivities to gaps or fabrication tolerances that need to be considered in the reload analysis. Chapter 3 also compares the various neutronics codes - WIMS-E, PHOENIX-L, and MCNP - to assess any special modeling sensitivities that need to be considered. The analyses are presented as scoping studies and as supporting evidence for the reload safety evaluation, rather than as a direct assessment of the general design criteria. In order to establish the acceptability of operation with TPBAR LTAs in the reactor core, the reload analysis must demonstrate that the facility remains in compliance with 10 CFR Part 50. This will be verified during the staffs review of the Tennessee Valley Authority's (TVA's) application for an amendment to the facility operating license for Watts Bar.

\subsection{Effects on Reactor Nuclear Design}

In Section 3.1 of its report, DOE states that the TPBAR LTAs will have minimal impact on the commercial core. The primary model used in the neutronics scoping studies of the TPBARs is the WIMS-E computer code, a two-dimensional, multi-group, integral-transport model.

Although not an NRC-approved methodology, WIMS-E was benchmarked by Pacific Northwest National Laboratory (PNNL) in a study of the light-water reactor concept for a DOE production reactor. The model used design characteristics of $17 \times 17$ fuel assemblies and large Westinghouse pressurized-water reactors (PWRs). WIMS-E was compared to MCNP (Monte Carlo N-Particle) Transport Code Version 4A for benchmarking purposes. Each code uses an independent set of nuclear cross-sections and different calculation methodologies. The Monte Carlo technique is generally considered the most accurate method for computing reactivity. The comparison demonstrates the adequacy of the WIMS-E model of the TPBAR. Therefore, differences in the calculated reactivity are expected and considered to be small. The DOE report states that a complete three-dimensional model of the host reload core with the LTAs will be performed by TVA and Westinghouse using an NRC-approved core design methodology.

The DOE report proposes that mimicking, to the extent feasible, the behavior of BPRAs ensures that the TPBARs will have minimal impact on the overall core design. This mimicking would be 
accomplished by using a limited number of TPBARs in any one fuel assembly, by using a limited number of LTAs in the core, and by placing LTAs in core regions that are not limiting with respect to core thermal-hydraulic performance.

However, the DOE report does not contain a comparison of the reactivity characteristics of the TPBARs with the BPRAs. Instead, a comparison of the infinite medium multiplication factor $\left(k_{\infty}\right)$ for TPBARs and WABAs as a function of burnup is shown in Figure 3-1 of the DOE report. In this case, the close comparison between these two designs is a general indication that other core design parameters are also similar. This analysis illustrates that differences are small enough to be accommodated within the range of core-to-core variations that are customarily handled in fuel cycle design. However, the scoping analysis does not present a basis for ensuring that all core design limits are satisfied. The staff concludes that the Watts Bar license amendment request must contain a comparison of the reactivity characteristics of the TPBAR to the BPRAs in order to demonstrate that the TPBARs are functionally similar to the BPRAs.

\subsection{Effects on Power Distribution}

In Section 3.2 of its report, DOE evaluates the sensitivity of flux peaking on pellet gaps and fabrication tolerances. The revised DOE report states that the impact of TPBARs on overall power distribution will be similar to the impact of BPRAs and WABAs currently used in PWRs. TPBAR absorber pellets are contained in pencils, which are stacked in a column in the TPBAR. The interfaces between the pencils result in gaps between segments of absorber pellet material. Each gap produces a small local axial power peak in the adjacent fuel rods. Gaps are affected by manufacturing tolerances, temperature, and irradiation.

The peak pellet gap is calculated with DORT, a discrete ordinate transport code. This method should accurately represent the effect of an absence of absorber on the surrounding fuel pins. The staff notes that the maximum gap was calculated to be less than 400 mils. A 400-mil gap in the absorber pellet stack results in a relatively small local power peak of 4.5 percent in the surrounding fuel pins. As part of its application for an amendment to the facility operating license for Watts Bar, TVA must demonstrate that the effect of the 400-mil maximum gap on the Watts Bar core is acceptable.

An analysis of fabrication tolerances using the WIMS-E model assessed the effect of variations in TPBAR dimensional tolerances, ${ }^{6} \mathrm{Li}$ loading tolerances, and impurity specifications. Power peaking as a result of TPBAR fabrication tolerances was less than 1 percent. This peaking is small compared to other flux perturbation effects. Since it is assumed that the LTAs will not be placed in peak locations, the staff believes that peaking effects of less than 1 percent caused by fabrication tolerances are not likely to exceed fuel design limits, based on past experience with other reactor cores. The staff will verify that the peaking effects due to fabrication tolerances will not cause the fuel design limits to be exceeded during the staff's review of TVA's application for an amendment to the facility operating license for Watts Bar. 


\subsection{Effects on Control Requirements}

In Section 3.3 of its report, DOE discusses the overall reactivity contribution of ${ }^{6} \mathrm{Li}$ in the LTA and its similarity to that of regular burnable absorber rod assemblies. The staff notes that the most significant difference in the behavior of the TPBAR is the decay of tritium to a strong absorber, ${ }^{3} \mathrm{He}$. As discussed in the January 22, 1997, public meeting, the effect of tritium decay during a long shutdown near the end of a cycle might result in more negative reactivity in the TPBARs than in a comparable WABA or BPRA. The DOE report indicates that the tritium decay is being included in the PHOENIX-L upgrade, which is discussed in Section 3.4 of this safety evaluation, below. The staff believes that the Watts Bar reload analysis should consider a case that assesses the maximum negative worth of the TPBAR LTA. This case could be near the end of cycle following a long shutdown rather than the usual beginning-of-life case. Because of the number and proposed location of LTAs in the prototypical irradiation, the staff would expect the effect to be small and that no limiting conditions would be introduced. However, this will be confirmed during the staff's review of TVA's application for an amendment to the facility operating license for Watts Bar.

\subsection{Changes in Reload Safety Analysis}

In Section 3.4 of its report, DOE discusses the change in the standard suite of NRC-approved Westinghouse core analysis codes (PHOENIX/ANC) to account for the presence of the TPBAR in the core. In a letter dated May 17, 1988, the NRC staff approved the Westinghouse Topical Report WCAP-11596, "Qualification of the PHOENIX-P/ANC Nuclear Design System for Pressurized Water Reactor Cores," for use. Only the PHOENIX-P code, which is one of the $\mathrm{NRC}$-approved Westinghouse core analysis codes, will be altered slightly to accommodate the presence of the TPBARs in the core. The proposed changes to the PHOENIX-P code model the depletion of ${ }^{6} \mathrm{Li}$ in the TPBARs, the decay of ${ }^{3} \mathrm{H}$, and the production/depletion of ${ }^{3} \mathrm{He}$.

Westinghouse will document the new version, PHOENIX-L, in a report to PNNL and TVA, subject to the reporting criteria imposed by 10 CFR 50.46(a)(3). Westinghouse will maintain computer software verification and validation files on PHOENIX-L. The staff has asked Westinghouse to describe (in a letter to the staff) the specific changes to the PHOENIX-P code and the results of the benchmarking. The staff will review the letter from Westinghouse, discussing the changes to the PHOENIX-P code, as part of its review of TVA's application for an amendment to the facility operating license for Watts Bar.

The DOE report makes several comparisons between PHOENIX-L and WIMS-E in order to assess the reactivity as a function of fuel depletion. A number of studies compare the infinite medium multiplication factor $\left(\mathrm{k}_{\infty}\right)$ as a function of burnup for various combinations of components. The staff notes that the studies show very good agreement between the codes. However, although the comparisons do not constitute a validation of the PHOENIX-L version, they do support the conclusion that use of PHOENIX-L does not introduce any significant degradation in predictions. The DOE report also indicates that the PHOENIX-L version will be benchmarked against the MCNP code in the Westinghouse verification and validation process. 


\subsection{Summary}

In Section 3.5 of its report, DOE concludes that the TPBARs mimic the neutronic behavior of BPRAs and WABAs and that the plant-specific reload safety analysis will demonstrate that all established fuel design limits will be met. On the basis of this information, the staff concludes that the scoping analysis offers evidence that the TPBARs and the WABAs are functionally similar, but does not present a basis for assuring that all core design limits are satisfied.

As part of its application for an amendment to the facility operating license for Watts Bar, TVA should include the following:

(1) the Cycle-2 reload analysis;

(2) a comparison of the reactivity characteristics of the TPBAR and the BPRA, since they are dimensionally similar;

(3) an analysis of the effect of a 400-mil gap in the absorber pellet stack to demonstrate that a local power peak of 4.5 percent in the surrounding fuel pins will be the maximum achieved;

(4) a case that assesses the maximum negative worth of the TPBAR LTA;

(5) benchmarking of the PHOENIX-L code.

Since the reload core analysis is not complete, the staff cannot determine whether unreviewed safety questions exist in the TPBAR nuclear design. 


\section{THERMAL AND HYDRAULIC DESIGN}

Chapter 4 of the Department of Energy (DOE) report addresses the impact of the tritiumproducing burnable absorber rod (TPBAR) lead test assembly (LTA) on the Watts Bar reactor core thermal-hydraulic design.

\subsection{TPBAR Thermal-Hydraulic Design}

Section 4.1 of the DOE report presents the thermal-hydraulic design criteria for TPBARs. Three of the four criteria are the same for burnable poison rod assemblies (BPRAs) and wet annular burnable assemblies (WABAs). The design criteria are as follows:

(1) The maximum TPBAR coolant outlet temperature from the guide thimble must not exceed the coolant bulk boiling temperature during Condition I (normal operation and operational transients) events.

(2) The maximum TPBAR cladding temperature must not exceed the temperature associated with the onset of subcooled nucleate boiling during Condition I and II (faults of moderate frequency) events.

(3) The core bypass flow through the guide thimbles must be limited to ensure that sufficient coolant flow is provided to the fuel rod channels to meet fuel and thermal-hydraulic design criteria.

(4) The TPBARs must not be placed (inserted) in a limiting core location.

The fourth provision is standard for any LTA. As discussed in Chapter 2 of the DOE report, the TPBARs are designed to withstand the same core temperatures as other reactor core components. As the dimensions of a TPBAR are similar to those of a BPRA, bypass flow in the guide tube is nominally the same. Guide tubes in the fuel assembly not used for TPBARs are plugged with standard Westinghouse thimble plugs. The total flow through guide tubes containing a TPBAR LTA is expected to be similar to flow for a standard BPRA. The argument for hydrodynamic stability is also based on the similarity of design parameters. Since the dimensions, heating, and mechanical characteristics of the TPBAR in a guide tube channel are the same as for the BPRA, the hydrodynamic stability is likely to be the same for Condition I and II events.

The DOE report states that the thermal-hydraulic analysis of the TPBAR design was performed by hand calculations and MATHCAD software. These calculations were not presented in the report; however, Tables 4-2 and 4-3 of the report summarize some of the Watts Bar parameters that were used in the thermal-hydraulic analysis. The staff notes that these parameters appear to 
be Cycle 1 parameters. As noted in Table 4-2 of the report, Cycle 2 parameters increase slightly but have not yet been entirely established. On the basis of this preliminary analysis, the DOE report states that the thermal-hydraulic criteria are met with the TPBAR located in an assembly with a total power peaking of up to 1.42 and with the TPBAR adjacent to a fuel rod with an $F_{d h}$ (enthalpy-rise hot channel factor) of 1.65 or less. Since the analysis, i.e., the hand calculations, was not presented in the DOE report, the staff cannot conclude at this time that the thermalhydraulic criteria are met with TPBARs located in assemblies discussed above. The staff will review the Cycle-2 thermal-hydraulic analysis as part of its review of the Tennessee Valley Authority's (TVA's) application for an amendment to the facility operating license for Watts Bar.

\subsection{Impact on Reactor Core Thermal-Hydraulic Design}

In Section 4.2 of the its report, DOE states that the thermal and hydraulic design parameters for Watts Bar were used as evaluation points to determine if any impacts of the TPBAR LTA on the reactor core thermal-hydraulic design would exist. DOE presents these parameters in Table 4-4. The staff notes that no parameter of the core design is changed by the TPBAR LTAs, except that the TPBARs have a slightly higher power than the BPRAs. Section 4.3 of the DOE report concludes that the thermal and hydraulic design bases of the TPBARs ensure that the TPBAR cladding will not be breached during Condition I and II events. DOE bases this statement on the assumption that the TPBAR LTAs will not be placed in a limiting position in the core. The staff cannot conclude, on the basis of the information provided in the DOE report, that the TPBAR LTAs will not affect the Watts Bar thermal-hydraulic design, with the TPBAR located in an assembly with a total power peaking of up to 1.42 and with the TPBAR adjacent to a fuel rod with an $F_{d h}$ of 1.65 or less. Since the DOE thermal-hydraulic analysis is preliminary, it is the host facility's responsibility to determine whether the thermal-hydraulic behavior of the TPBAR LTAs located in non-limiting positions in the core represents an unreviewed safety question, as defined in 10 CFR 50.59(a)(2). As stated above, the staff will review the Cycle-2 thermalhydraulic analysis as part of its review of TVA's application for an amendment to the facility operating license for Watts Bar. 


\section{MATERIALS}

The lead test assembly (LTA) materials were selected so that the properties satisfy the functional requirements and compatibility requirements of the other reactor components, reactor coolant, emergency core cooling fluids, fuel pool components, and fuel pool cooling systems. Chapter 5 of the Department of Energy (DOE) report addresses materials specifications (Section 5.1), materials properties (Section 5.2), materials performance (Section 5.3), and nondestructive examination (Section 5.4).

\subsection{Materials Specifications}

In Section 5.1 of its report, DOE states that the LTA is constructed of materials that have been chosen for their ability to perform successfully considering results from in-reactor and ex-reactor test programs, and for their compatibility with the other internal reactor components, fuel assemblies, the reactor coolant system, fuel pool components, and fuel pool cooling systems. The LTA hold-down assembly is a Westinghouse component used in burnable poison rod assemblies (BPRAs) and is, therefore, not unique to the LTA. The materials of the tritium producing burnable absorber rod (TPBAR) have been selected to reflect design characteristics suitable for the production and retention of tritium. Earlier tritium target rod designs were irradiated in the Advanced Test Reactor. On the basis of experience with those designs, material requirements for the tritium-producing rods have continued to evolve. DOE states that numerous improved design features and materials have been incorporated into the TPBAR to ensure that the functional requirements will be met.

DOE states that quality standards for material selection, fabrication, handling, storage, and inspection are specified to ensure that important functions are maintained. To verify that materials are in compliance with specifications, materials and components are subjected to quality inspections by the vendor and by Pacific Northwest National Laboratory (PNNL). The venders prepare certified material test reports (CMTRs) for all TPBAR components.

DOE presents information based on results from in-reactor and ex-reactor test programs, and for the materials' compatibility with the other reactor internal components, fuel assemblies, the reactor coolant system, fuel pool components, and the fuel pool cooling system. This information offers reasonable assurance that the materials chosen for this program will perform successfully in the TPBAR. The staff notes that some changes may be required in the quality standards, as mentioned in the discussions on Section 2 of this safety evaluation. DOE must evaluate the effects of thermal cycling, particularly on the cladding and cladding coating as noted by the Advisory Committee on Reactor Safeguards (ACRS) (discussed later in this section). Finally, consideration needs to be given to metal-metal and intermetallic interactions during design-basis accidents, also as suggested by the ACRS. 


\subsection{Materials Properties}

The properties of TPBAR materials are given in the Materials Property Handbook (MPH). The properties indexed in the MPH are listed in Table 5-2 of the DOE report. The MPH was used for the design and analysis of the TPBAR cladding, and component dimensions were specified to prevent interactions caused by thermal expansion, irradiation growth, and swelling. The cladding and components were designed to prevent excessive changes in dimensions that could lead to degradation. . The design is described in Chapter 2 of DOE's report.

As discussed in Section 2 of this safety evaluation, DOE has presented sufficient information to give reasonable assurance that there will be no adverse interactions caused by thermal expansion, irradiation growth, and swelling. Further evidence of no adverse interactions comes from operating experience with austenitic stainless steel fuel cladding at Northeast Utilities' Haddam Neck plant, Southern California Edison's San Onofre Unit 1, Consumers Power Company's Big Rock Point plant, and Dairyland Power Cooperative's La Crosse plant.

\subsection{Materials Performance}

In Section 5.3 of its report, DOE addresses the materials performance aspects of TPBAR design. The key materials that enable a TPBAR to generate and store tritium are: (1) permeation-resistant Type 316 stainless steel (316 SS) barrier-coated cladding and end plugs, (2) oxidation-resistant nickel-plated Zircaloy-4 getters, (3) lithium aluminate absorber pellets, and (4) Zircaloy-4 liner. Other materials are the American Society for Testing and Materials (ASTM) 302 stainless steel (302 SS) spring and helium gas. The opportunity for material degradation of the TPBAR is limited by the in-core residence period of one fuel cycle.

\subsubsection{Cladding and End Plug Material}

The TPBAR design has evolved from years of operating experience at a number of reactors. 316 SS has been the material historically used for tritium target cladding. Processes for permeation barrier application were developed using 316 SS cladding. Sufficient experimental and performance data for barrier-coated tubing using other materials are not available. $316 \mathrm{SS}$ with 20-percent cold-worked (CW) was specified to establish adequate strength while staying within the experience base established for 300 -series SS.

A 20-percent CW 316 SS was specified for all TPBAR components that form the pressure boundary (cladding and end plugs) with the reactor coolant. Tubing used for fabrication of the TPBAR is seamless (non-welded). When compared with 304 SS, which has been extensively used in pressurized-water reactors (PWRs) for BPRA cladding and fuel cladding, $316 \mathrm{SS}$ exhibits better general corrosion resistance and better resistance to pitting corrosion, higher resistance to transgranular stress corrosion cracking (TGSCC) and to intergranular stress corrosion cracking 
(IGSCC) in aggressive environments, and greater strength and resistance to creep. Figure 5-1 of the DOE report shows that the allowable stress for the ASTM A 771316 SS between 100 (38 $\left.{ }^{\circ} \mathrm{C}\right)$ and $850^{\circ} \mathrm{F}\left(454^{\circ} \mathrm{C}\right)$ is much higher than the allowable stress for $304 \mathrm{SS}$.

The most commonly used austenitic stainless steel in the nuclear industry is 304 SS. This material has a nominal composition of 19-percent chromium, 9-percent nickel, 1-percent manganese, and up to 0.08 -percent carbon. This material is used for cladding in dummy fuel pins that shield reactor vessel walls from radiation damage, for active fuel pins, for reactor vessel cladding, for primary coolant system piping and valves, and as fuel cladding in four domestic PWRs. A significant increase in corrosion resistance is achieved by using 316 SS instead of 304 SS. Type $316 \mathrm{SS}$ has a nominal composition of 17-percent chromium, 12-percent nickel, 2.5percent molybdenum, 1-percent manganese, and up to 0.08-percent carbon. The molybdenum addition gives the 316 SS improved corrosion resistance and also provides higher creep, stressto-rupture, and tensile strength at elevated temperatures. Type $316 \mathrm{SS}$ has been used in nuclear piping, pumps, valves, and previous tritium target cladding.

\section{Coolant/316 SS Compatibility}

Section 5.3.1.1 of the DOE report states that $316 \mathrm{SS}$ is compatible with the reactor system primary coolant. Experience in operating PWR and boiling-water reactor (BWR) plants with stainless steel cladding of fuel rods, control rods, and structural components (e.g., end-plate castings and support grids) confirms that uniform corrosion of stainless steel is negligible; less than 0.0001 in. per year $(2.5 \mu \mathrm{m}$ per year). DOE states that the cladding wastage in a commercial light-water reactor (CLWR) caused by uniform corrosion of the TPBAR external surface during 550 effective full power days (EFPDs) is less than 0.0003 in. $(7.6 \mu \mathrm{m})$.

DOE has presented sufficient calculational results, test results, and operating experience to adequately assure that the corrosion rate of the TPBAR components will be negligible and that the TPBAR components are compatible with the primary coolant. Furthermore, there is considerable operational experience in commercial reactor coolant systems with austenitic stainless steel to give assurance that these steels are compatible with the primary coolant.

As discussed in Sections 2.2.1 and 2.2.6 of this safety evaluation, the staff has asked DOE to provide additional information concerning the effect of thermal cycling on TPBAR components and metal-metal and intermetallic interactions during a design basis accident. This information must be included as part of the Tennessee Valley Authority's (TVA's) application for an amendment to the facility operating license for Watts Bar.

\section{Stress Corrosion Cracking}

Section 5.3.1.2 of the DOE report states that stress corrosion cracking (SCC) in 300-series stainless steel requires: (1) thermal sensitization or irradiation-induced susceptibility, (2) high 
stresses (near or above the yield stress), and (3) an aggressive environment (e.g., reactive species such as oxygen, chloride, and/or fluoride in an aqueous medium at concentrations much higher than typical levels in PWR coolant; typical levels are less than 5 ppb oxygen, less than 50 ppb chloride, and less than $50 \mathrm{ppb}$ fluoride). Each of these factors is described below.

\section{- Materials Susceptibility}

Thermal treatments in the temperature range of $800^{\circ} \mathrm{F}\left(425^{\circ} \mathrm{C}\right)$ to $1500{ }^{\circ} \mathrm{F}\left(815^{\circ} \mathrm{C}\right)$ have the potential to sensitize 304 or $316 \mathrm{SS}$. The process of applying an aluminide coating to the internal surface of TPBAR cladding requires temperatures within this range. Therefore, TPBAR cladding may be thermally sensitized, depending on the actual carbon content of the $316 \mathrm{SS}$ and the time that the $316 \mathrm{SS}$ is held in the sensitizing temperature range.

Irradiation of 300 -series SS to neutron fluences greater than 1 to $2 \times 10^{22} \mathrm{n} / \mathrm{cm}^{2}$ (E less than $1 \mathrm{MeV}$ ) may decrease chromium $(\mathrm{Cr})$ concentrations at grain boundaries by promoting $\mathrm{Cr}$ diffusion away from the grain boundary region, thereby increasing the susceptibility to SCC. The peak neutron fluence expected for the TPBAR cladding is approximately $5 \times 10^{21} \mathrm{n} / \mathrm{cm}^{2}$ (E less than $1 \mathrm{MeV}$ ). Therefore, TPBAR cladding may be subject to some reduction in grain boundary $\mathrm{Cr}$ during irradiation, resulting in irradiationinduced susceptibility to SCC. However, the PWR environment would not cause SCC.

\section{- Stress}

The TPBAR design inner pressure limit of 3000 psia $(20.7 \mathrm{MPa})$ is approximately 750 psi (5.2 MPa) above the reactor system external pressure of $2250 \mathrm{psia}(15.5 \mathrm{MPa}$ ). Therefore, the tensile hoop stresses from internal pressurization remain very low throughout the period of irradiation. Material considerations related to design-basis . accidents are discussed in Section 2.2.1 of this safety evaluation. Irradiation-induced swelling of the pellets and irradiation growth of the getters are insufficient to stress the cladding. The absorber pellets remain intact during irradiation. Absorber pellets generally do not fracture, but if a pellet fractured, localized stresses in the cladding from interaction of the cladding with pellet fragments would be prevented by the intervention of the getter, which confines the absorber pellet material. The thin walls of the absorber pellets, nominally 0.040 in. $(1 \mathrm{~mm})$, will prevent mechanical damage from interaction between pellets and cladding, such as could result from fracturing of solid absorber pellets or fuel. The stress in the TPBAR is insufficient to cause or propagate SCC.

\section{- Environment}

DOE states that the external operating environment for the TPBAR during irradiation will be standard PWR coolant maintained within Technical Specification chemistry limits for 
oxygen and reactive compounds. Austenitic stainless steel is not considered susceptible to attack in this environment. Severely sensitized stainless steels do not undergo any intergranular attack in Westinghouse PWR coolant environments. Issues such as boiling, crevices, highly borated solutions, and stagnant flow, which can result in more severe environmental conditions, are not present in the TPBAR operating environment.

DOE states that, during reactor shutdown and cooldown, the TPBAR cladding is not susceptible to $\mathrm{SCC}$ because the temperature is below $200^{\circ} \mathrm{F}\left(93^{\circ} \mathrm{C}\right)$ and the stresses are low. Experience with SS-clad spent nuclear fuel at temperatures below $200^{\circ} \mathrm{F}\left(93^{\circ} \mathrm{C}\right)$ has shown that for storage periods up to 25 years, there is no measurable degradation of stainless steel cladding in pool water typical of PWR spent fuel pools.

Although the TPBAR material may become sensitized or susceptible, SCC is not anticipated because a TPBAR has very low tension stress and the reactor coolant chemistry control program ensures a non-aggressive environment.

The staff concludes that DOE has presented analyses and operating experience to give adequate assurance that the stainless steel components will be resistant to SCC in PWR environments, particularly since they are only required to survive one operating cycle. It is unlikely that the stainless steel components would fail in one operating cycle even if they were highly susceptible and in a higher oxygen environment. Operating experience in commercial nuclear reactors lends support to this conclusion.

The ACRS raised several issues at the March 7, 1997, presentation by DOE. The issues are that DOE's report does not address the effects of thermal cycling during postulated design-basis accidents (DBAs) on the materials, particularly on the cladding and the aluminide barrier. Also, DOE has not discussed whether any metal-metal or intermetallic interactions that could result in the development of brittle microstructures will occur during postulated DBAs. Discussion is also needed on temperature limits for metal-metal and intermetallic interactions and the failure mechanism as a result of these interactions. The staff concludes that information on these issues will have to be evaluated before it can reach a conclusion on the acceptability of irradiating LTAs containing TPBARs in any facility licensed by the Nuclear Regulatory Commission. DOE has agreed to investigate these issues and to give the findings of their investigation to ACRS and the staff.

\section{Effect of Barrier Coating on Cladding Performance}

Section 5.3.1.3 of the DOE report states that the strength of the barrier-coated cladding is adequate to prevent buckling of the cladding at the beginning of life (BOL) before a TPBAR has generated sufficient internal pressure to support the external coolant pressure.

The staff concludes that, as discussed previously in Section 2 of this safety evaluation, DOE has presented analyses and test data to give reasonable assurance that the cladding will not buckle before internal pressure develops. 
Furthermore, the experience with stainless steel cladding at Palisades in dummy fuel pins and at Haddam Neck, Big Rock Point, San Onofre Unit 1, and La Crosse indicates that the cladding will not buckle.

\section{Results of Cladding Burst Tests}

Section 5.3.1.4 of the DOE report states that cladding burst tests were conducted to support evaluation of cladding performance under DBAs. The test results shown in Figure 5-2 of the DOE report indicate that the burst stresses and temperatures for uncoated 20-percent coldworked $(\mathrm{CW})$ tubing and for coated cladding are indistinguishable. Therefore, burst tests conducted on 20-percent CW tubing (or on heat-treated cladding that simulates the coating process) are applicable to barrier-coated cladding used in TPBARs.

DOE states that, for the operating design pressure of 3000 psia $(20.7 \mathrm{MPa})$, the hoop stress at $1500^{\circ} \mathrm{F}\left(815^{\circ} \mathrm{C}\right)$ is $43,800 \mathrm{psi}(302 \mathrm{MPa})$. These pressure-temperature conditions approach the cladding breach curve presented in Figure 5-2 of the DOE report. These results indicate that $1500^{\circ} \mathrm{F}$ is a threshold temperature for burst of TPBAR cladding. In all of these burst tests, the cladding strain exceeded 6 percent, considerably in excess of the 1-percent minimum strain design criterion to ensure adequate cladding ductility.

DOE's experimental burst test data indicate that the limiting temperature before the cladding will burst is in the vicinity of $1500^{\circ} \mathrm{F}$. These results indicate that the cladding would burst during a design-basis large-break loss-of-coolant accident (LBLOCA). The consequences of a burst of the cladding are discussed in Section 6.3 .3 of this safety evaluation.

\section{Weld Qualification}

Section 5.3.1.5 of the DOE report states that the internal contents are contained by plugs that are welded to each end of the TPBAR cladding. DOE states that welding forms a sound metallurgical and structural joint between the end plug and the stainless steel cladding, and weld preparation of the cladding involves removing the aluminide barrier in the weld region to avoid alloying the weldment with aluminum. The welding procedure specifies the requirements for welding operator qualification and the welding process parameters to produce weldments that meet specifications. Weldment quality is tested in accordance with (1) American Society for Testing and Materials Standard E2 (ASTM E2) for metallographic examination, (2) American Society of Mechanical Engineers (ASME) requirements for helium leak testing, (3) internal PNNL specifications, and (4) radiographic examination.

DOE states that the TPBAR end plugs are attached to the cladding by means of an autogenic (no filler metal added) weld process; therefore, DOE finds that the conditions of Regulatory Guide 1.31 do not apply.

On the basis of the information in the DOE report, the staff concludes that the weld qualification procedure for TPBARs is deficient. Since the TPBAR is considered safety-related, the welder 
qualification and weld process specification must conform to the requirements of Section IX of the ASME Code, as well as to additional requirements of the construction code, owners specifications, and the additional requirements for special processes of NQA-1 and the Westinghouse quality assurance (QA) program. The DOE report does not address which construction code will be used for welder qualification and weld process specifications. ASTM E2 is no longer an approved standard; it was replaced in 1982 by ASTM E883. ASTM E883 describes how to conduct metallographic examinations, and its use for examining these welds needs to be described in more detail. Therefore, TVA must supplement the welding procedure described in Section 5.3.1.5 of the DOE report to address these concerns before the staff can conclude that TPBAR LTA irradiation in the Watts Bar reactor is acceptable.

\section{Hydrogen Isotope Permeation}

In Section 5.3.1.6 of its report, DOE states that the inner surface of the cladding is aluminized to limit the permeation of tritium through the cladding into the reactor coolant and the permeation of hydrogen from the coolant into the TPBAR. This is achieved by applying an aluminumized barrier on the inner surface of the cladding.

DOE's conclusion that the use of an aluminized barrier to limit the permeation of tritium through the cladding is based on its on prior experience with this coating in DOE reactors.

\section{Materials Compatibility}

Section 5.3.1.7 of the DOE report states that the TPBAR materials do not interact chemically below their melting temperatures indicated in the MPH. DOE further states that (1) the stainless steel cladding provides structural strength to withstand reactor irradiation, flow, pressure, and temperature conditions, and (2) in-reactor and ex-reactor test results indicate that the aluminide barrier will not peel or blister.

Should a TPBAR become water-logged from a cladding breach (an abnormal event), DOE states that aluminum, chlorine, suspended solids, tritium, and helium would be released when the aluminide barrier on the inner surface of the cladding dissolves. A very small quantity of nickel contained in the getter will dissolve when it is exposed to reactor coolant. DOE states that for simultaneous breach of 32 TPBARS, the maximum concentrations released to the reactor coolant are predicted to occur between 200 and 300 hours following the breach; and the maximum contributions are orders of magnitude below the reactor coolant system (RCS) chemistry limits. Therefore, cladding breach of 32 TPBARs would not affect the chemistry of the reactor coolant. The effects of tritium release to the reactor coolant are assessed in Chapter 6 of the DOE report.

The staff concludes that DOE has provided sufficient analyses and ex-reactor and in-reactor data to give reasonable assurance that the TPBAR materials are compatible with RCS coolant for one operating cycle. 


\subsubsection{Pencils}

The TPBAR's main internal subassemblies, shown in Figure 2-2 of the DOE report, are a stack of subcomponents, referred to as "pencils." The cylindrical getters serve as the outer structure for

the pencils. The pencils are coined on the ends to confine the absorber pellets, but are not hermetically sealed.

\subsubsection{Absorber Pellets}

Within each pencil is a stack of right-cylindrical, high-density, annular, lithium aluminate $\left(\mathrm{LiAlO}_{2}\right)$ absorber pellets enriched with ${ }^{6} \mathrm{Li}$. The concentration of ${ }^{6} \mathrm{Li}$ is 25 to 33 percent, but higher or lower concentrations of ${ }^{6} \mathrm{Li}$ can be accommodated. DOE states that the physical properties of absorber pellets are insensitive to the ${ }^{6} \mathrm{Li}$ content. The absorber pellets are ceramic and have a melting point of $3182^{\circ} \mathrm{F}\left(1750^{\circ} \mathrm{C}\right)$, a temperature that is not expected to be reached during normal operating or DBA conditions.

\section{Absorber Pellet Mechanical Properties}

In Section 5.3.3.1 of its report, DOE states that strength, density, irradiation, swelling, and gas release affect the mechanical performance of pellets. The absorber pellets are resistant to thermal shock. Thermal shocking of the pellets by rapid increase from ambient temperature to $1652^{\circ} \mathrm{F}$ $\left(900^{\circ} \mathrm{C}\right)$ within 2 minutes did not have an observable effect on microstructure or strength. DOE states that the axial compressive fracture strength of absorber pellets is in the range of $80,000 \mathrm{psi}$ $(550 \mathrm{MPa})$ to $130,000 \mathrm{psi}(900 \mathrm{MPa})$ at ambient temperature, as indicated in Figure $5-3$ of the DOE report. The increased fracture strength shown in Figure 5-3 for several pellets tested at $1652^{\circ} \mathrm{F}\left(900^{\circ} \mathrm{C}\right)$ was caused by the onset of high- temperature plasticity.

DOE states that pellets are capable of withstanding loads of 150 pounds per linear inch (26.8 $\mathrm{kg} / \mathrm{cm}$ ) applied in the radial direction. The mechanical strength of the pellets supports the conclusion that they will withstand shipping and handling load requirements without sustaining damage.

DOE has presented test data to provide reasonable assurance that the absorber pellets have sufficient strength and thermal shock resistance to survive an operating cycle and to survive shipping and handling load requirements without damage. DOE also submitted calculations that indicate that the melting temperature of the pellets will not be exceeded during normal operating and DBA conditions. 


\section{Absorber Pellet Irradiation Performance}

In Section 5.3.3.2 of its report, DOE states that, as shown in Table 5-1 of the DOE report, the absorber pellets evaluated by post-irradiation examinations (PIEs) were intact after irradiation to 154 to 239 gas volume ratio (GVR). Only minor microcracking, negligible grain growth, and small (less than $1 \mu \mathrm{m}$ ) as-fabricated porosity was observed. Therefore, pellet disintegration, major cracking, or redistribution is not expected below the TPBAR peak design goal of 215 GVR. In Chapter 2 of its report, DOE discusses the GVR expected during in-core residence.

DOE states that gas retention in absorber pellets depends on production rate and temperature. The absorber pellets release approximately 97 percent of the generated helium. During irradiation, the pellets retain some tritium, to the extent of 30 to $40 \mathrm{Ci}$ per cc.

DOE states that absorber pellets are insoluble and do not disintegrate in water. Therefore, in the event of a cladding breach, absorber pellets remain intact and lithium is not redistributed.

DOE submitted test data based on the observations of the pellets after irradiation. These data provide reasonable assurance that the absorber pellets will perform as intended.

\subsubsection{Getter}

DOE states that the pencils are enclosed by a getter tube of Zircaloy-4 plated with nickel. The getter maintains a low tritium partial pressure by absorbing tritium as it is released from the absorber pellets. The nickel protects the Zircaloy -4 from oxidation, thereby enhancing the absorption of tritium.

\subsubsection{Liner}

DOE states that absorber pellets generally do not fragment, but, if fragments were generated, the Zircaloy-4 liner provides additional assurance that the fragments will be confined. The liner functions to control oxygen and moisture by reacting with $\mathrm{T}_{2} \mathrm{O}$ and $\mathrm{H}_{2} \mathrm{O}$. Zircaloy- 4 liners are insoluble in water and have no effect on the reactor coolant in the event of a cladding breach.

\subsubsection{Plenum Subassembly and Getter Disk}

As illustrated in Figure 2-2 of the DOE report, the plenum subassembly contains a 302 SS spring enclosed by a getter tube, with an upper getter disk attached to the lower end of the getter tube. The plenum subassembly is supported by the top pencil and prevents axial movement of the pencils during TPBAR shipping and handling. The spring is similar to springs in PWR fuel rods and BPRAs. Because the weld areas and the top and bottom end plugs are not coated, the upper getter tube and getter disk and the lower getter disk maintain low tritium pressure at the extremities of the TPBAR. DOE states that these materials will not dissolve in water. 


\subsubsection{LTA Hold-Down Assembly}

The hold-down assembly (shown in Figure 2-1 of the DOE report) is supplied by Westinghouse and meets Westinghouse material specifications.

DOE submitted sufficient test data to offer reasonable assurance that the getters, liners, plenum subassembly and getter disk, and LTA hold-down assemblies will not be damaged by the primary coolant for one operating cycle, and that any fragmentation of the absorber pellets will be confined by the Zircaloy-4 liners.

\subsection{Nondestructive Examination}

DOE states that nondestructive examination (NDE) of tubular products and fittings must be sufficient to ensure that the critical characteristics of the material meet specified acceptance criteria. DOE inspects TPBAR materials and components for compliance with specifications. Potential inspection methods range from standard visual inspections to discrete and unique methodologies specific to particular characteristics of a component.

DOE states that, although the internal components of each rod serve distinct functions for the production of tritium, the rod's cladding and end plugs form the pressure boundary between the TPBAR components and the reactor coolant system. The principal methods employed to examine the TPBAR cladding and end plugs are ultrasonic, eddy current, radiography, and helium leak testing. DOE states that the cladding and end plugs are tested in conformance with applicable codes and standards. After the barrier coating is applied, NDEs are performed to verify the acceptability of the barrier coating in terms of such key parameters as the thickness, integrity, and consistency. Table 5-5 of the DOE report notes the NDE techniques and applicable standards used during TPBAR fabrication. DOE also states that contamination of the TPBARs is minimized during assembly, and that testing performed before shipment confirms that the specified cleanliness requirements are met.

The staff concludes that, since the TPBAR is being classified as safety- related and is being produced to the criteria of Section III of the ASME Code, the NDE techniques and applicable standards should conform to the requirements of Section III, or an alternative to the requirements must be submitted to the NRC for approval under Title 10 of the Code of Federal Regulations, Section 50.55a (10 CFR 50.55a). Since DOE states that the TPBARs are being designed to the 1995 edition of the code, the staff concludes that the NDE techniques performed by PNNL and by subvendors should be qualified to the requirements of Section XI, Appendix VIII or to an acceptable alternative proposed under 10 CFR $50.55 \mathrm{a}$.

\subsection{Conclusions}

The staff has reviewed the materials used in the TPBAR and agrees that they are adequate for the LTA. On the basis of experimental results and operating experience in domestic nuclear power plants, the staff finds that the materials in the TPBAR will not be affected by the environment 
and will not be adversely affected during Conditions I to IV ${ }^{2}$, with the possible exception of thermal cycling. Austenitic stainless steel has been used for more than 100 operating years as a fuel cladding with no adverse reaction with the primary coolant.

The staff agrees that the cladding will fail during an LBLOCA and that there may be metal-metal or intermetallic interactions during DBAs. The consequences of cladding failure would be inconsequential, as discussed in Section 6 of this safety evaluation.

The staff identified potential deficiencies in the weld qualification program in terms of adherence to the requirements of Section IX of the ASME Code. Furthermore, the proposed nondestructive examination methods do not conform to the requirements of Section III of the ASME Code. Before these methods can be used at Watts Bar, TVA must submit a relief request to the NRC in accordance with the provisions of 10 CFR $50.55 \mathrm{a}$.

${ }^{2}$ Condition I = normal operation and operational transients, Condition II = faults of moderate frequency; Condition III = infrequent faults; Condition IV = limiting faults 


\section{OPERATIONAL IMPACTS OF LTAS}

Chapter 6 of the Department of Energy (DOE) report addresses the operational impacts of tritium-producing burnable absorber rod (TPBAR) lead test assemblies (LTAs) with respect to normal operations, refueling operations, off-normal events, and accidents. The main impact on normal and abnormal operation is the leakage of tritium from the TPBARs. Even in normal operation with full integrity of the cladding and a permeation-resistant barrier, tritium cannot be completely contained because tritium diffuses through the TPBAR cladding material. The staff notes that the analyses presented are narrative in nature and no calculations are presented. The licensee, Tennessee Valley Authority (TVA), will have to determine whether the installation of the TPBAR LTAs into the Watts Bar reactor will affect normal and refueling operations or the accident analyses described in Chapter 15 of the Watts Bar Final Safety Analysis Report (FSAR). The staff will review the potential impacts as part of its review of TVA's application for an amendment to the facility operating license for Watts Bar.

\subsection{Normal Operations}

In Section 6.1 of its report, DOE calculates the increase in tritium inventory in the primary coolant and the incremental increase in radiological release from the plant due to the design goal release rate from all 32 TPBARs. The design goal of less than $6.7 \mathrm{Ci}(248 \mathrm{GBq})$ per year for a single TPBAR correlates to an annual tritium release to the reactor coolant system (RCS) of 214 $\mathrm{Ci}(7.96 \mathrm{TBq})$ for all 32 rods. The staff notes that the design goal is a parameter established to meet specific DOE, environmental safety and health, and occupational safety requirements. DOE expects that actual tritium leakage from the TPBARs will be below this value. On the basis of the maximum tritium inventory in the RCS for Watts Bar during Cycle $1,0.712 \mu \mathrm{Ci}$ per $\mathrm{g}$ (26.3 Bq per $\mathrm{kg}$ ), the impact of design goal tritium leakage from the TPBARs on the tritium inventory in the RCS would be a 25-percent increase. However, the staff notes that any tritium that is released from the TPBARs during normal operations would be distributed throughout the RCS, chemical and volume control system, liquid radwaste system, and gaseous radwaste system, and processed along with the rest of the coolant. Any release to the environment from normal operations must be within the limits specified in 10 CFR Part 50, Appendix I.

\subsection{Refueling Operations}

\subsubsection{TPBAR Assembly Storage in Fuel Pool or New Fuel Storage}

In Section 6.2 .1 of its report, DOE briefly discusses the placement of the TPBAR LTAs into Watts Bar's new fuel storage area or spent fuel pool preceding irradiation and in the spent fuel pool after irradiation. The revised DOE report states that the LTAs with the TPBARs weigh less than a fuel assembly containing 24 burnable poison rod assemblies (BPRAs). Therefore, DOE 
states that the current seismic analysis for the fuel storage racks bounds the analysis for racks containing the TPBAR LTAs.

The DOE report states that 150 hours after reactor shutdown, the heat load of each LTA is less than $0.024 \mathrm{~kW}$ ( $3 \mathrm{~W}$ per pin). The total heat load to the spent fuel pool from all four LTAs after irradiation should not increase significantly from normal assemblies with BPRAs and should be within the capability of the Watts Bar spent fuel pool cooling system. The staff notes that theTPBARs will not remain in the spent fuel pool for very long. The TPBARs will be removed from the fuel assemblies and shipped off-site once the refueling outage is complete. However, the staff believes that the increase in heat load to the spent fuel pool will be neglible even if the irradiated TPBARs remain in the spent fuel pool indefinitely. The staff will confirm this capability during its review of TVA's amendment to the facility operating license for Watts Bar.

\subsubsection{Onsite TPBAR Assembly Movement and Handling}

.In Section 6.2.2 of its report, DOE states that the loading and shipping of the TPBAR LTAs will be completed in accordance with the administrative policies and procedures at Watts Bar. The staff notes that no special tools are needed for loading or removing TPBAR LTAs, since the dimensions and the handling features of the TPBAR are identical to those of conventional BPRAs. Current procedures for handling BPRAs are applicable to TPBARs. Therefore, there are no special mechanical concerns with the proposed TPBAR movement and handling. The radiological consequences of breaching the cladding of the TPBAR during movement and handling are discussed in Section 6.3.3 of this safety evaluation.

\subsubsection{Occupational Exposure During Refueling}

The TPBARs are designed to have minimal effect on plant operations, including refueling operations. Preceding irradiation, it may be necessary to assemble the LTAs; however, as the unirradiated TPBARs are essentially "not radioactive," they will produce no increase in exposure, occupational or non-occupational.

After irradiation, the TPBARs are expected to contain some 370,000 Ci (13.7 PBq) of tritium $\left({ }^{3} \mathrm{H}\right)$. This is far more tritium, but far less radioactivity, than that produced by the reactor core. The tritium does not pose a particular threat because (1) tritium emits only a low-energy $\left(\mathrm{E}_{\max }=\right.$ $0.0186 \mathrm{MeV}$ ) beta and (2) the tritium is bound in the TPBARs. Some of the tritium beta energy is converted into $\mathrm{x}$ rays (bremsstrahlung) but $370,000 \mathrm{Ci}$ of tritium produces less photon energy than is produced by $1 \mathrm{Ci}(37 \mathrm{GBq})$ of ${ }^{137} \mathrm{Cs}$ and the ${ }^{137} \mathrm{Cs}$ radiation is much more penetrating. The spent fuel removed for refueling contains about a million curies of ${ }^{137} \mathrm{Cs}$ and many other nuclides. Thus, the effect of tritium as a source of external radiation in the reactor environment is negligible.

Tritium in this quantity could be a potential problem if it were released from the TPBPRs; however, the DOE report states that the release can be expected to be limited to $6.7 \mathrm{Ci}(248 \mathrm{GBq})$ per rod annually, which constitutes a total release rate of less than $215 \mathrm{Ci}$ ( $7.96 \mathrm{TBq}$ ) per year for 
all the TPBPRs. This quantity is consistent with the nominal amounts of tritium expected in pressurized water reactor (PWR) coolant systems. The NRC licensing calculation, the GALE code, predicts about $250 \mathrm{Ci}(9.25 \mathrm{TBq})$ of tritium in the reactor coolant and tritium releases to the environment from large PWRs are averaging over $600 \mathrm{Ci}(22.2 \mathrm{TBq})$ per year per reactor and ranging as high as 4,000 $\mathrm{Ci}(148 \mathrm{TBq})$ per year without exceeding regulatory limits. Thus, the TPBARs might produce an observable but not dramatic increase in the tritium concentration in the spent fuel pool. Increasing the tritium in the spent fuel pool could increase occupational exposure but, since tritium exposure is not an important contributor to occupational exposure (according to NRC data summarized in NUREG-0713), the increase would be expected to be negligible. This is consistent with the results reported in the DOE report.

The staff concludes that the TPBARs could cause some increase in occupational radiation exposure. However, this increase would be negligible and would not constitute a safety, or an "as low as is reasonably achievable" (ALARA), concern.

\subsection{Offnormal Events}

In Section 6.3 of its report, DOE addresses a number of offnormal events, including the effects of TPBAR absorber relocation, cladding defects, radiological consequenses of a TPBAR cladding breach, inadvertent loading and operation with an LTA in an improper position in the core, and anticipated transient without scram (ATWS) events.

\subsubsection{Impacts of TPBAR Absorber Relocation}

Section 6.3 .1 of DOE's report pertains to the physical form of the absorber pellets during the irradiation cycle. As discussed in Chapter 2 of DOE's report, the absorber pellets are not expected to undergo densification or significant phase changes over the range of temperatures during Condition I, II, III, and IV $\mathrm{V}^{3}$ events. Therefore, relocation of the absorber pellets does not appear to be a concern.

\subsubsection{TPBAR Cladding Defects}

DOE states that the TPBAR cladding is made from Type 316 stainless steel material (316 SS), which is stronger and more corrosion resistant than $304 \mathrm{SS}$. During manufacture, the TPBARs will be subjected to tests and inspections to ensure that cladding defects do not occur.

DOE states that if a cladding defect does exist, the amount of contaminants released to the reactor coolant system (RCS) will remain below normal chemistry limits and will not degrade other components. The absorber pellets would lose a microscopic layer of lithium to the coolant

${ }^{3}$ Condition I = normal operation and operational transients, Condition II = faults of moderate frequency; Condition III = infrequent faults; Conditiion IV = limiting faults 
due to leaching. There is no loss of the absorber materials comparable to the $\mathrm{B}_{4} \mathrm{C}$ leaching from a wet annular burnable absorber (WABA) pellet.

The staff concludes that DOE has presented procedures to give adequate assurance that any cladding defects in the $316 \mathrm{SS}$ cladding will be identified during the testing and inspections. In the event that a cladding defect is not identified, DOE has demonstrated that the amount of contaminants released will remain below normal chemistry limits and will not result in degradation of other components.

\subsubsection{Radiological Consequences of a TPBAR Cladding Breach}

In the event of a cladding breach, tritium would be released to the reactor coolant water. Because tritium is hydrogen, it tends to be retained in the water. A cladding breach in the spent fuel pool is possible, but less likely, and the consequences would be less severe because the lower temperature would result in less tritium being released (see Section 6.4 .1 of this safety evaluation, below). Experience (NUREG-2859) shows that tritium releases to the environment occur predominantly in liquid effluents; e.g. from normal operations at the Sequoyah nuclear plant in 1993, more than 90 percent of the tritium release was in liquid effluents. In evaluating this event, DOE postulates the complete release of the tritium from 1 TPBAR, about $12,000 \mathrm{Ci}$ $(444 \mathrm{TBq})$, with $20,000 \mathrm{gpm}\left(=4 \times 10^{10} \mathrm{~L}\right)$ dilution, resulting in an average concentration of $3 \mathrm{x}$ $10^{-7} \mathrm{Ci}$ per liter $\left(=3 \times 10^{-4} \mu \mathrm{Ci}\right.$ per milliliter). This average concentration is well below the instantaneous concentration limit established for most nuclear power plants, including Watts Bar. Because most liquid releases are batch releases, it would be necessary for the licensee to implement a control program to ensure that the instantaneous concentration limit is not exceeded. As this is true for all releases, the TPBAR cladding failure would not impose new requirements on the licensee.

The average concentration of $3 \times 10^{-4} \mu \mathrm{Ci}$ per milliliter is far too high to be acceptable under the dose constraints related to $\$ 50.36(\mathrm{a})$ and Appendix I to Part 50. For Watts Bar, this does not constitute a problem because, for the dose calculations, the effective concentration is further reduced by "near field dilution" of $1000 \mathrm{cfs}\left(=7 \times 10^{11} \mathrm{~L}\right.$ per year $)$, resulting in an average concentration of $1.7 \times 10^{-5} \mu \mathrm{Ci}$ per milliliter. Furthermore, the only exposure modes available at Watts Bar are the fish, drinking water, and shoreline pathways. Tritium produces no dose by the shoreline pathway. The "maximum individual" $(\mathrm{H})$ dose by the fish pathway is:

$$
H=1.7 \times 10^{-5}\left(\frac{\mu C i}{m L}\right) 0.9\left(\frac{m L}{g m}\right) 21,000\left(\frac{g m}{y r}\right) 0.105\left(\frac{m r e m}{\mu C i}\right) 1(y r)=0.034 \quad \text { (mrem) }
$$

For Watts Bar, there may be another factor of 10 dilution for the drinking water pathway (because the nearest drinking water intake is far downstream), but at this concentration, the above dose is increased by a factor $(\mathrm{F})$ of 


$$
\mathrm{F}=730 /(21 \times 0.9)=39
$$

The resulting total dose would be $1.35 \mathrm{mrem}(13.5 \mu \mathrm{Sv})$, which is less than half the dose criterion. (Since tritium is distributed throughout the body, the dose calculated is the committed dose equivalent and it is compared to the most limiting annual dose criterion from Appendix I to 10 CFR Part 50 , which is 3 mrem ( $30 \mu \mathrm{Sv})$ to the whole body.)

If it is assumed that 10 percent of the tritium released from the TPBAR is released to the atmosphere, the methodology of the Watts Bar offsite dose calculation manual (ODCM) for the breathing, milk, meat, and vegetable pathways gives estimates of the dose as about $0.5 \mathrm{mrem}$ (5 $\mu \mathrm{Sv})$. This is a small fraction of the relevant Appendix I dose criterion of $5 \mathrm{mrem}(50 \mu \mathrm{Sv})$ in a year.

The staff concludes that Watts Bar could continue to operate and comply with the offsite dose criteria after a TPBAR cladding breach.

\subsubsection{Inadvertent Loading and Operation of an LTA in an Improper Position}

In Section 6.3 .4 of its report, DOE states that LTA loading errors are precluded by the Watts Bar administrative procedures that are in place to prevent fuel assembly and burnable poison misloading. These procedures confirm the final core configuration via video tape. The DOE report states that in the unlikely event that an LTA is loaded in the wrong location, the resulting power distribution will be detectable by the in-core movable detector system or the core power distribution perturbation will be within the specified fuel design limits. However, it is not clear to the staff whether this misloading was assumed to be a limiting location. The purpose of this analysis is to verify that misloading the TPBAR LTA to a limiting location is within the limits of the safety analysis report. Also Chapter 3 of the DOE report discusses how the TPBARs are designed to mimic the reactivity characteristics of the BPRAs. Therefore, it is not clear how the in-core detectors would be able to distinguish the TPBARs from the BPRAs.

In addition, the DOE report states that the thermal-hydraulic analysis in Chapter 4 demonstrates that the LTA would not exceed the TPBAR design limits even if it were loaded in the limiting fuel assembly in the core. The staff is unable to concur with these conclusions on the basis of the information presented in the DOE report. DOE's analysis in Chapter 4 is preliminary and states that the thermal-hydraulic criteria are met with the TPBAR located in an assembly with a total power peaking of up to 1.42 and with the TPBAR adjacent to a fuel rod with an $F_{d h}$ (enthalpy hot-channel factor) of 1.65 or less. As noted in Table 4-4 of the DOE report, TPBARs have a slightly higher power than the BPRAs. Therefore, placement of the TPBAR LTAs in a location other than described, and thus more limiting, must be analyzed. The staff is concerned that the thermal-hydraulic behavior of the TPBAR LTAs located in limiting positions in the core could increase the probability of occurrence or the consequences of an accident previously evaluated in the safety analysis report, or could reduce a margin of safety. Therefore, on the basis of the 
information presented by DOE, the staff cannot determine whether the inadvertent loading and operation of an LTA in an improper position in the core presents an unreviewed safety question. TVA must submit information evaluating the consequences of loading the LTA in the limiting assembly in the core before the staff can determine whether TPBAR irradiation is acceptable at Watts Bar.

\subsubsection{Anticipated Transient Without Scram (ATWS)}

In Section 6.3.5 of its report, DOE discusses the TPBAR LTA impact on ATWS events. The DOE report states that the TPBARs could affect the reactivity assumptions of the ATWS analysis, although this effect would be minimal due to the ${ }^{6} \mathrm{Li}$ cross-section. As stated in Chapter 3 , the TPBARs are designed to mimic the neutronic behavior of conventional BPRAs and, therefore, the TPBARs are not expected to affect the existing ATWS neutronics analysis. The staff is unable to conclude that the TPBARs will have minimal impact on the ATWS neutronics analysis, based on the information presented by DOE. The staff will verify that the installation of the TPBAR LTAs in the Watts Bar core will not result in an unanalyzed condition with regard to ATWS during its review of TVA's application for an amendment to the facility operating license for Watts Bar.

\subsection{Accidents}

In its report, DOE has addressed the effects of a TPBAR on postulated accidents, including a TPBAR assembly dropped during refueling, radiological consequences of release of reactor coolant (steam generator tube rupture or steamline break), and TPBAR damage and radiological consequences during a design-basis loss-of-coolant accident.

\subsubsection{Impacts of a Dropped LTA}

In Section 6.4.1 of its report, DOE has addressed the effects of a TPBAR assembly dropped during refueling operations. There is no significant radioactivity in an unirradiated TPBAR. If an irradiated LTA were dropped, it would be under several feet of water because of the administrative controls in current procedures at pressurized-water reactors (PWRs). DOE states that the TPBAR LTA weighs less than a fuel assembly with 24 BPRAs; therefore, the effect of dropping a TPBAR on fuel, racks, or other equipment in the reactor pool or fuel handling pool is bounded by the existing analysis. The DOE report implies that the consequences of such an accident would likely be limited to damage to the LTA, resulting in a possible breach of the cladding. If the impact damaged an irradiated LTA, it would initiate or exacerbate tritium leakage.

DOE estimates that, because of the distribution of the tritium in the LTA, a small release (tens of curies) could occur quickly, but that the bulk of the tritium would not be released for some time, giving the licensee ample time for placing the damaged LTA in a container (preventing further 
release to the environment). The tritium released immediately would largely be retained in the spent fuel pool water. The addition of a few tens of curies of tritium to the spent fuel pool water would not have a significant effect on doses, either occupational or offsite.

To provide an estimate of the consequences, the staff has analyzed the prompt release of $100 \mathrm{Ci}$ (3.7 TBq) of tritium to the atmosphere. For Watts Bar, atmospheric dispersion is taken as $1.8 \mathrm{x}$ $10^{-4} \mathrm{sec} \mathrm{m}^{-3}$. The resulting maximum individual dose $(\mathrm{H})$ would be:

$$
H=1.8 \times 10^{-4}\left(\frac{\mathrm{sec}}{\mathrm{m}^{3}}\right) 100(\mathrm{Ci}) 3.47 \times 10^{-4}\left(\frac{\mathrm{m}^{3}}{\mathrm{sec}}\right) 64\left(\frac{\mathrm{rem}}{C i}\right)=4 \times 10^{-4} \quad(\mathrm{rem})
$$

A worker in the fuel handling building might be more highly exposed, but, on the basis of the staff's analysis, the dose is not expected to exceed 5 mrem $(50 \mu \mathrm{Sv})$.

On the basis of its analysis, the staff concludes that the radiological impact of a dropped LTA would not be significant.

\subsubsection{Impacts of Design Tritium Leakage on Radiological Consequences of a Steam Generator Tube Rupture or Steamline Break}

In Section 6.4.2 of its report, DOE addresses these events and their impact on the TPBARs. DOE states that the RCS pressure and temperature caused by a locked rotor event are much more severe than the conditions from a steam generator tube rupture or main-steamline break events. Thus, neither of these events is expected to damage a TPBAR. However, normal leakage from TPBARs is expected to add tritium to the primary coolant. By the end of core life, the TPBARs could have added some $300 \mathrm{Ci}(11 \mathrm{TBq})$ of tritium. If all this tritium were released to the atmosphere at Watts Bar, the maximum offsite dose would be about $1.2 \mathrm{mrem}(12 \mu \mathrm{Sv})$. The addition of 1.2 mrem to the doses projected to occur in the event of such an accident from other radionuclides would not likely cause the total dose to exceed the dose criterion in Section 6.4 of NUREG-0800 (the Standard Review Plan) for these accidents, which is 2500 mrem ( $25 \mathrm{mSv}$ ) to the whole body.

On the basis of its analysis, the staff concludes that the presence of the TPBARs would not contribute significantly to the radiological consequences of these accidents.

\subsubsection{Impacts of LTAs in the Event of a LOCA}

In Section 6.4.3 of its report, DOE discusses the potential failure of the TPBARs during design basis loss-of-coolant accident (DBLOCA) events. DOE states that the TPBAR stresses do not 
exceed the stresses from temperature and pressure that occur during the small-break loss-ofcoolant accident (SBLOCA) at Watts Bar. Therefore, the TPBAR is not assumed to fail during the SBLOCA at Watts Bar.

DOE states that, for the large-break loss-of-coolant accident (LBLOCA), the maximum core temperature does exceed the TPBAR stresses and could damage the TPBARs. DOE considers the LBLOCA to be the most limiting accident with regard to potential TPBAR failure. The staff has calculated an upper bound estimate of the radiological consequence of the resulting tritium release by assuming the release of the entire inventory of $370,000 \mathrm{Ci}(13.7 \mathrm{PBq})$ to containment. Using the Watts Bar parameters, containment leakage is at the rate of 0.25 percent per day for 2 hours, which would result in the release to the atmosphere of about $77 \mathrm{Ci}(2.8 \mathrm{TBq})$ of tritium. The resulting dose at the exclusion area boundary would be about $0.3 \mathrm{mrem}(3 \mu \mathrm{Sv})$. Although not zero, this dose is negligible in comparison to either the 10 CFR Part 100 dose criterion of $25,000 \mathrm{mrem}(250 \mathrm{mSv})$, or the dose calculated for the LBLOCA without the TPBARs, and thus would not cause the dose criteria to be exceeded. However, because an increase in offsite dose is anticipated, this increase in offsite dose represents an increase in the consequences of an accident previously evaluated in the safety analysis report and, therefore, this potential increase requires prior NRC approval.

For the LBLOCA, 10 CFR 50.46 requires that the emergency core cooling system maintain the following: (1) peak cladding temperature to less than $2200^{\circ} \mathrm{F}\left(1204{ }^{\circ} \mathrm{C}\right),(2)$ total oxidation of the cladding to less than 17 percent of the total cladding thickness before oxidation, (3) maximum hydrogen generation to less than 1 percent, (4) coolable geometry, and (5) long-term cooling. Since the maximum design temperature for TPBARs is $1500^{\circ} \mathrm{F}\left(816^{\circ} \mathrm{C}\right)$, localized TPBAR cladding failure or rupture is assumed for the LBLOCA. However, the staff believes that the requirements of 10 CFR 50.46 are maintained because of the limited number of TPBAR LTAs in the core. The DOE report states that the effect of TPBARs and the additional tritium on the combustible gas inventory following a LOCA is negligible. In addition, the maximum stored inventory of tritium in TPBAR LTAs is a very small fraction of the hydrogen that would be released from a zirconium-water reaction. Consequently, TPBARs would have no significant contribution to combustible gas in a LOCA. The tritium released to the coolant would not be released as a gas and, therefore, would not produce an increase in hydrogen concentration. On this basis, the staff has confidence that the requirements of 10 CFR 50.46 will continue to be met following an LBLOCA.

\subsection{Summary}

During its review of Chapter 6 of DOE's report, the staff has determined that because there is an increase, although negligible, in offsite radiological impact of LTAs in the event of a LOCA, a licensee must seek prior NRC approval for this change. This issue is discussed in Section 6.4.3, above. 
In addition, the staff concludes that additional analyses must be provided concerning inadvertent loading and operation of an LTA in an improper position, as discussed in Section 6.3.4, above. TVA must submit information evaluating the consequences of loading the LTA in the limiting assembly in the core before the staff can determine whether TPBAR irradiation is acceptable at Watts Bar. 


\section{QUALITY ASSURANCE}

The staff is continuing its review of Chapter 7 of the Department of Energy's (DOE's) report to determine whether DOE's quality assurance (QA) program controls are adequate to establish conformance with the requirements of 10 CFR Part 50, Appendix B. Fundamental issues concerning the safety classification of specific components in the tritium-producing burnable absorber rod (TPBAR) lead test assemblies (LTAs), commercial-grade dedication, design information controls, and the adequacy of Pacific Northwest National Laboratory's (PNNL's) QA program related to the design and manufacture of TPBARs remain unresolved.

Although DOE has not requested that NRC review and approve PNNL's QA plan, the fact that PNNL is identified as maintaining primary responsibility for the design and fabrication of the TPBARs establishes that an evaluation of PNNL's QA program will constitute an integral component of the staff's review of the TPBAR LTA program as applied to commercial lightwater reactors. Therefore, the staff will conduct onsite inspections at PNNL in order to verify the adequate implementation of $10 \mathrm{CFR}$ Part 50, Appendix B requirements related to the design and fabrication of the TPBARs.

Because the Tennessee Valley Authority's Watts Bar plant has been selected as the location for the confirmatory TPBAR LTA irradiation, TVA will need to provide TPBAR suppliers (PNNL and the Westinghouse fuels fabrication facility in Columbia, South Carolina) with the programmatic controls and processes that will demonstrate compliance with the requirements of 10 CFR Part 50, Appendix B, before installing these assemblies into the Watts Bar reactor core. 


\section{SECURITY OF CLASSIFIED MATTER}

In Chapter 8 of its report, the Department of Energy (DOE) addresses transportation and physical security aspects of tritium-producing burnable absorber rod (TPBAR) lead test assemblies (LTAs). DOE states that the TPBARs and some related documentation necessary for utility nuclear safety committee review will be classified "confidential restricted data." As classified matter, they require measures to prevent diversion of, unauthorized access to, and disclosure of classified information.

\subsection{Transportation of Classified Hardware}

DOE states that the TPBARs will be brought to the site by a DOE-approved carrier that meets Department of Transportation requirements for shipment of nuclear fuel. Once inside the protected area, movement of TPBARs will be monitored by personnel who have DOE clearances. While the TPBAR LTAs are stored in the new fuel storage racks or in the fuel pool, a suitable level of protection will be provided.

\subsection{Control of Classified Documents and Hardware}

Because the TPBAR hardware and certain of the documentation are classified, licensees undertaking irradiation of TPBAR LTAs will have to meet the requirements for access to confidential restricted data specified in 10 CFR Parts 25 and 95, and Section 50.37. By letter dated October 4, 1996, DOE advised the staff that a limited number of licensee employees at Westinghouse Nuclear Fuels and at the Tennessee Valley Authority (TVA) needed access authorization in order for them to perform their responsibilities in support of the DOE Commercial Light-Water Reactor (CLWR) Project. DOE proposed that it perform the necessary personnel security clearance function and process a limited number of "L" and "Q" access authorizations for these licensee employees. By letter dated November 1, 1996, the staff agreed with DOE's proposal and stated that no additional NRC clearance is required to satisfy the requirements of $10 \mathrm{CFR} 50.37$ and $54.17(\mathrm{~g})$. This is consistent with the memorandum of understanding between the NRC and DOE, dated September 19, 1996, concerning provisions of the National Industrial Security Program.

DOE has stated that no classified documents related to the TPBARs will be maintained on site at Watts Bar or at TVA headquarters. A reading room is being maintained at Oak Ridge National Laboratory so that individuals with a "need to know" will have access to the classified documents associated with the CLWR Program.

With regard to the facility (security) clearance (FCL), following discussions between DOE Office of Safeguards and Security and the NRC Division of Facilities and Security, the staff and 
DOE have agreed to allow DOE to perform the "cognizant security agency" responsibilities applicable to the protection of classified matter at NRC-licensed facilities involved with the TPBAR LTA irradiation. These facilities include the Westinghouse fuels facility at Columbia, Industrial Security Program," dated September 19, 1996.) In its letter dated April 18, 1997, the staff summarized the agreement and stated that DOE would have authority over the FCL at the Westinghouse, Columbia and Watts Bar facilities during the LTA irradiation phase of DOE's program for the production of tritium in CLWRs. As agreed, DOE will provide the NRC with South Carolina, and TVA's Watts Bar plant. (The functions of the "cognizant security agency" are delineated in the "Memorandum of Understanding Between the Department of Energy and the United States Nuclear Regulatory Commission Under the Provisions of the National copies of the DOE-approved security plans for these facilities, invite NRC to participate in facility security reviews, and keep the NRC Division of Facilities and Security fully and currently apprised of security and classification matters at these facilities. The letter also informed DOE. that the agreement and the decision regarding future overall security responsibility for this program will be re-evaluated following completion of the LTA irradiation phase. 


\section{REGULATORY ANALYSIS}

The provisions of 10 CFR 50.59 allow operating license holders to make changes to their facility as described in the facility safety analysis report (SAR), to implement changes to facility procedures described in the SAR, and to conduct tests or experiments not described in the SAR without prior NRC approval if the change, test, or experiment does not involve a change to the Technical Specifications (TS) and does not involve an unreviewed safety question. A proposed change, test, or experiment involves an unreviewed safety question (1) if it increases the probability of occurrence or the consequences of an accident previously evaluated in the SAR, (2) if it creates the possibility for an accident of a different type from any evaluated previously, or (3) if it reduces a margin of safety, as defined in the basis for any technical specification.

Because the Department of Energy (DOE) has announced the selection of the Tennessee Valley Authority's (TVA's) Watts Bar plant as the facility at which the one-time confirmatory test of conponents that could be used in the production of tritium will be conducted, the staff shifted the focus of its review to evaluate the proposed tritium-producing burnable absorber rod (TPBAR) lead test assembly (LTA) irradiation at Watts Bar.

\subsection{Effect on Plant Technical Specifications}

In Section 9.1 of its revised report, DOE states that no provisions of the Watts Bar TS were viewed as prohibiting the irradiation of a limited number of LTAs containing TPBARs. DOE states that the Watts Bar TS titled "Design Features - Reactor Core" allows a limited number of LTAs to be placed in nonlimiting regions of the core. DOE also states that operation of the Watts Bar reload core with TPBAR LTAs will be within the core design limits of the TS titled "Power Distribution Limits" for Watts Bar.

The staff has reviewed the Watts Bar TS and concludes that nothing in the TS specifically prohibits operation of the facility with TPBAR LTAs in the core. Therefore, no changes to the Watts Bar TS are required. However, as noted in Section 9.3, below, an amendment to the facility operating license will be required because irradiation of LTAs containing TPBARs requires NRC review and approval.

\subsection{Effect on Plant Final Safety Analysis Report}

The confirmatory test of irradiating a limited number of TPBAR LTAs in the Watts Bar reactor will require revisions to the Watts Bar SAR. Also, TVA and Westinghouse, as part of the reload safety analysis for Watts Bar, must verify that operation within existing core design limits can be accomplished with the TPBAR LTAs installed in the core. 
Some changes to the SAR sections dealing with radiological consequences will be necessary. Although the radiological impacts of TPBAR irradiation are small, the changes in the dose due to the TPBARs are not zero and must be described.

In addition, the staff has identified a number of issues for which TVA will have to provide additional information in its SAR for Watts Bar in order to support a request for an amendment to the facility operating license that would allow the staff to determine that TPBAR LTA irradiation is acceptable at that facility. These issues are summarized in Section 10.2 of this safety evaluation.

\subsection{Licensing Impact}

The staff has identified issues requiring prior NRC review and approval. Therefore, the provisions of 10 CFR 50.59, allowing certain actions by licensees without prior NRC approval, do not apply. The staff concludes that TVA must submit a request for an amendment to the facility operating license for Watts Bar and receive NRC approval before inserting TPBAR LTAs into the Watts Bar reactor core. 


\section{SUMMARY AND CONCLUSIONS}

The staff has reviewed the Department of Energy's (DOE's) report and supporting information concerning the tritium-producing burnable absorber rod (TPBAR) lead test assembly (LTA). Many technical issues have been satisfactorily addressed in the DOE report, as documented in this safety evaluation.

During its review, the staff identified an issue that requires further NRC review. Therefore, the staff does not concur with DOE's position that a limited number of LTAs containing TPBARs can be irradiated in a commercial light-water reactor (CLWR) under the provisions of 10 CFR Part 50.59, without prior NRC approval. The staff also needs additional information on several issues before it can determine whether additional unreviewed safety questions are involved.

On February 7, 1997, DOE announced the selection of the Tennessee Valley Authority's (TVA's) Watts Bar plant as the facility that will conduct the one-time confirmatory test of components that could be used in the production of tritium. Accordingly, the staff shifted the focus of its review to evaluate the proposed TPBAR LTA irradiation at Watts Bar.

The staff concludes that should TVA wish to irradiate LTAs containing TPBARs at the Watts Bar facility, it must first submit an application for an amendment to the facility operating license for Watts Bar to permit such irradiation.

\subsection{Issues Requiring Further NRC Review}

During its review, the staff has identified an issue involving the offsite radiological impact of LTAs in the event of a design basis loss-of-coolant accident (LOCA) that requires further NRC review. This issue is discussed in Section 6.4 .3 of this safety evaluation.

Because the staff has identified an issue requiring further NRC review during its review of DOE's proposal to conduct the confirmatory test of irradiating TPBAR LTAs in a CLWR, TVA must submit an application for an amendment to its facility operating license for Watts Bar before inserting TPBAR LTAs into the reactor core.

\subsection{Issues Requiring Additional Analysis}

The staff has identified a number of areas in which TVA will have to supplement the information in the DOE report before the staff can determine whether the proposed irradiation is acceptable at Watts Bar. These are listed below, along with the section(s) of this safety evaluation in which each is discussed. 
(1) use of the 1995 edition of the American Society of Mechanical Engineers (ASME) Boiler and Pressure Vessel Code (2.2.1)

(2) use of American Society for Testing and Materials (ASTM) Standard A 771 for the purchase of the cladding (2.2.1)

(3) effects of thermal cycling on TPBAR components and quality standards to address them $(2.2 .1,5.1)$

(4) metal-metal interactions occurring during a LOCA, including temperature limits and failure mechanisms that result from them $(2.2 .1,5.1)$

(5) demonstration that the MATHCAD model is conservative (2.2.5)

(6) comparison of reactivity characteristics of the TPBAR to burnable poison rod assemblies (3.1)

(7) Cycle-2 reload analysis (3)

(8) analysis of the 400-mil pellet gap (3.2)

(9) maximum negative worth of TPBAR LTA (3.3)

(10) benchmarking of PHOENIX-L code (3.4)

(11) thermal-hydraulic analysis for Cycle-2 $(4.1,4.2)$

(12) weld qualification procedure (5.3.1)

(13) nondestructive testing techniques and applicable standards (5.4)

(14) inadvertent loading and operation of an LTA in an improper position (6.3.4)

(15) quality-assurance program (7)

TVA must present additional information and analyses in these areas in its safety analysis accompanying the application for amendment to the facility operating license for Watts Bar. 


\section{APPENDIX A \\ CHRONOLOGY OF CORRESPONDENCE}

This appendix contains a chronological listing of correspondence between the NRC and DOE and other correspondence related to DOE's program for the production of tritium in commercial light-water reactors. All documents, with the exception of certain enclosures to correspondence marked with an asterisk $\left(^{*}\right)$ (denoting "confidential restricted data") have been placed in the Commission's Public Document Room, the Gelman Building, 2120 L Street, NW., Washington, D.C., under Project No. 697.

March 15, 1996

April 19, 1996

May 22, 1996

July 16,1996

August 26, 1996

September 30, 1996

October 3, 1996

October 4, 1996
SECY-96-058, "Memorandum of Understanding Between the Department of Energy and the Nuclear Regulatory Commission."

Staff requirements memorandum related to SECY-96-058, "Memorandum of Understanding Between the Department of Energy and the Nuclear Regulatory Commission."

"Memorandum of Understanding Between the Nuclear Regulatory Commission and the Department of Energy."

Letter from D. B. Matthews, NRC, to S. M. Sohinki, DOE, requesting use of Project No. 697 on all correspondence related to DOE's program for the CLWR production of tritium.

Letter from G. C. Sorensen, PNNL, to J. H. Wilson, NRC, transmitting white paper on stress corrosion cracking in 316 stainless steel cladding for PWR tritium-producing burnable absorber rods.

Reimbursible agreement between NRC and DOE for NRC review related to DOE's tritium program.

SECY-96-212, "Review of Department of Energy's Proposal for Tritium Production in Commercial Light-Water Reactors."

Letter from S. M. Sohinki, DOE, to T. M. Martin, NRC, regarding DOE clearances for NRC licensees supporting Tritium Program, Project No. 697. 
November 1, 1996

November 21, 1996*

December 4, 1996*

December 4, 1996

December 10, 1996

December 10, 1996

December 16, 1996

December 23, 1996

January 3, 1997

January 13,1997
Letter from T. M. Martin, NRC, to S. M. Sohinki, DOE, concerning DOE clearances for NRC licensees supporting tritium program.

Letter from S. M. Sohinki, DOE, to Document Control Desk, submitting draft classified report on tritium-producing burnable absorber rod lead test assembly.

Letter from S. M. Sohinki, DOE, to Document Control Desk, submitting classified version of tritium-producing burnable absorber rod lead test assembly topical report (supersedes draft report submitted on November 21, 1996).

Letter from S. M. Sohinki, DOE, to Document Control Desk, submitting unclassified version of tritium-producing burnable absorber rod lead test assembly topical report.

Staff requirements memorandum related to SECY-96-212, "Review of Department of Energy's Proposal for Tritium Production in Commercial Light-Water Reactors."

Letter from S. M. Sohinki, DOE, to Document Control Desk, providing correction to tritium-producing burnable absorber rod lead test assembly topical report (unclassiified version).

Letter from R. J. Guenther, PNNL, to S. M. Matthews, NRC, prioritizing the importance of components in tritium-producing burnable absorber rods.

Federal Register Notice 61 FR 67584, "Notice of Receipt of DOE Topical Report on Tritium Producing Burnable Poison Rod Lead Test Assemblies".

Letter from T. M. Martin, NRC, to S. M. Sohinki, DOE, transmitting the staff's request for additional information regarding DOE's report on the tritium-producing burnable absorber rod lead test assembly.

Letter from T. M. Martin, NRC, to S. M. Sohinki, DOE, transmitting the staff's supplemental request for additional information regarding DOE's report on the tritium-producing burnable absorber rod lead test assembly. 
January 21, 1997

January 24, 1997

January 25,1997

January 27,1997

February 4, 1997

February 5, 1997

February 7, 1997

February 13, 1997

February 14, 1997

February 24, 1997
Notice of public meeting on January 22, 1997, with DOE to discuss response to staff's requests for additional information concerning DOE's report on tritium-producing burnable absorber rod lead test assemblies.

Summary of public meeting held on January 22, 1997, to discuss response to staff's requests for additional information regarding DOE's report on tritium-producing burnable absorber rod lead test assemblies.

Letter from C. G. Frazier, DOE, to T. M. Martin, NRC, regarding draft request for proposal DE-RP02-97DP00414 for the commercial light-water reactor production of tritium.

Federal Register Notice 62 FR 3925, "Notice of Public Meeting on DOE's Proposal to Produce Tritium in Commercial Light-Water Reactors."

Letter from T. M. Martin, NRC, to S. M. Sohinki, DOE, transmitting guidance on benchmarking the VIPRE code to validate the implementation and user application of changes to accommodate the use of lithium burnable poison rods for the production of tritium.

Notice of public meeting with DOE on February 25, 1997, to provide the opportunity for public comment on DOE's program for the CLWR production of tritium.

Letter from S. M. Sohinki, DOE, to Document Control Desk, submitting additional information regarding the tritium-producing burnable absorber rod lead test assembly report.

Letter from T. M. Martin, NRC, to S. M. Sohinki, DOE, transmitting NRC staff's position on quality assurance requirements for tritium-producing burnable absorber rods.

Letter from S. M. Sohinki, DOE, to Document Control Desk, transmitting supplemental information regarding the tritiumproducing burnable absorber rod lead test assembly report.

Letter from T. M. Martin, NRC, to S. M. Sohinki, DOE, transmitting supplemental guidance on benchmarking the VIPRE 
February 28, 1997

March 3, 1997*

March 5, 1997

March 7, 1997

March 12, 1997

March 17, 1997

March 17, 1997

March 18, 1997

April 3, 1997

April 9, 1997 code to validate the implementation and user application of changes to accommodate the use of lithium burnable poison rods for the production of tritium.

Summary of February 25, 1997, public meeting on DOE's Program to Produce Tritium in Commercial Light-Water Reactors (including meeting transcript).

Letter from S. M. Sohinki, DOE, to Document Control Desk, submitting Revision 1 to the classified and proprietary version of the Lead Test Assembly Evaluation Report.

Letter from T. M. Martin, NRC, to S. M. Sohinki, DOE, concerning facilities security clearance at NRC-licensed facilities participating in DOE's program for tritium production. Letter from S. M. Sohinki, DOE, to Document Control Desk, transmitting revised responses to NRC requests for additional information and informational copy of PNNL project QA plan.

Letter from S. M. Sohinki, DOE, to Document Control Desk, transmitting requested information on failure modes and effects analysis and modifications made to the PHOENIX-P computer software.

Letter from S. M. Sohinki, DOE, to Document Control Desk, regarding response to NRC staff request for additional information on commercial light-water reactor lead test assembly report.

Letter from S. M. Sohinki, DOE, to Document Control Desk, submitting commercial light-water reactor lead test assembly unclassified technical report, Revision 1.

Letter from S. M. Sohinki, DOE, to Document Control Desk, regarding lead test assembly safeguards and security information.

Letter from S. M. Sohinki, DOE, to Document Control Desk, requesting NRC inspection of commercial light-water reactor program lead test assembly activities.

Letter from T. M. Martin, NRC, to S. M. Sohinki, DOE, transmitting ACRS scoping assessment of potential unreviewed safety questions associated with materials interactions for TPBAR LTAs. 


\section{TITLE AND SUBTITLE}

Safety Evaluation Report related to the Department of Energy's Proposal for the irradiation of lead test assemblies containing tritium-producing burnable absorber rods in commercial light-water reactors.

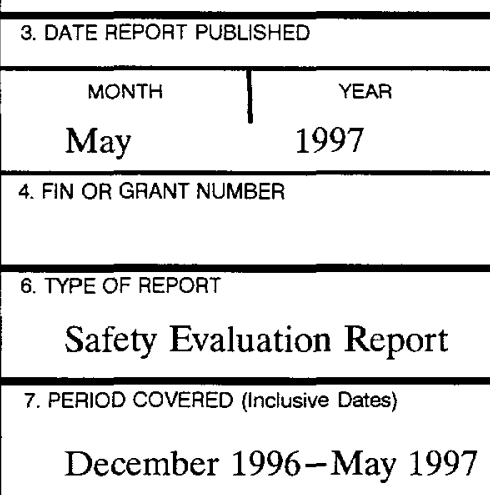

8 PERFORMING ORGANIZATION - NAME AND ADDRESS (If NAG, provide Division, Office or Region, U.S. Nuclear Regulatory Commission, and mailing address; if contractor, provide name and mailing address.)

Department of Reactor Program Management

Office of Nuclear Reactor Regulation

U.S. Nuclear Regulatory Commission

Washington, DC 20555-0001

9. SPONSORING ORGANIZATION - NAME AND ADDRESS (IF NRC, type "Same as above"; if contractor, provide NRC Division, Office or Region, U.S. Nuclear Regulatory Commission, and mailing address.)

Same as above

10. SUPPLEMENTARY NOTES

Project No. 697

11. ABSTRACT (200 words or less)

The NRC staff has reviewed a report, submitted by DOE to determine whether the use of a commercial light-water reactor (CLWR) to irradiate a limited number of tritium-producing burnable absorber rods (TPBARs) in lead test assemblies (LTAs) raises generic issues involving an unreviewed safety question. The staff has prepared this safety evaluation to address the acceptability of these LTAs in accordance with the provision of 10 CFR 50.59 without NRC licensing action.

As summarized in Section 10 of this safety evaluation, the staff has identified issues that require NRC review. The staff has also identified a number of areas in which an individual licensee undertaking irradiation of TPBAR LTAs will have to supplement the information in the DOE report before the staff can determine whether the proposed irradiation is acceptable at a particular facility.

The staff concludes that a licensee undertaking irradiation of TPBAR LTAs in a CLWR will have to submit an application for amendment to its facility operating license before inserting the LTAs into the reactor.

12. KEY WORDS/DESCRIPTORS (List word's or phrases that will assist researchers in locating the report.)

amendment to facility operating license commercial light-water reactor (CLWR)

Department of Energy

irradiation

lead test assembly (LTA)

tritium

tritium-producing burnable absorber rod (TPBAR)

10 CFR 50.59

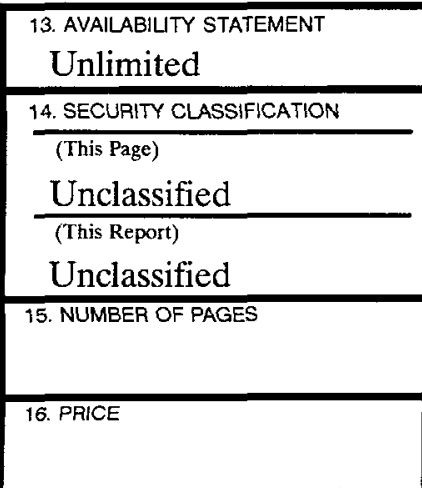


April 17, 1997

Letter from D. B. Matthews, NRC, to S. M. Sohinki, DOE, announcing inspection of procurement and fabrication activities at Pacific Northwest National Laboratory for the fabrication of TPBAR LTAs.

April 21, 1997

Letter from T. M. Martin, NRC, to S. M. Sohinki, DOE, transmitting a discussion of DOE's quality assurance program for tritium-producing burnable absorber rod lead test assemblies.

April 21, 1997

Letter from T. M. Martin, NRC, to S. M. Sohinki, DOE, concerning facilities security clearance at NRC-licensed facilities participating in LTA phase of DOE's program for tritium production. 